\title{
I-Optimal Design of Hierarchical 3D Scaffolds Produced by Combining Additive Manufacturing and Thermally Induced Phase Separation
}

\author{
Azizeh-Mitra Yousefi ${ }^{1,}$, Junyi Liu ${ }^{1}$, Riley Sheppard ${ }^{1}$, Songmi Koo ${ }^{1}, J^{\prime}$ shua Silverstein ${ }^{2}$, \\ Jing Zhang ${ }^{3}$, Paul F. James ${ }^{4}$ \\ ${ }^{1}$ Department of Chemical, Paper and Biomedical Engineering, Miami University, Oxford, $\mathrm{OH}$ \\ 45056 \\ ${ }^{2}$ Department of Geology, Miami University, Oxford, OH 45056 \\ ${ }^{3}$ Department of Statistics, Miami University, Oxford, OH 45056 \\ ${ }^{4}$ Department of Biology, Miami University, Oxford, $\mathrm{OH} 45056$
}

\begin{abstract}
The limitations in the transport of oxygen, nutrients, and metabolic waste products pose a challenge to the development of bioengineered bone of clinically relevant size. This paper reports the design and characterization of hierarchical macro/microporous scaffolds made of poly(lacticco-glycolic) acid and nanohydroxyapatite (PLGA/nHA). These scaffolds were produced by combining additive manufacturing (AM) and thermally induced phase separation (TIPS) techniques. Macrochannels with diameters of $\sim 300 \mu \mathrm{m}, \sim 380 \mu \mathrm{m}$, and $\sim 460 \mu \mathrm{m}$ were generated by embedding porous 3D-plotted polyethylene glycol (PEG) inside PLGA/nHA/1,4-dioxane or PLGA/1,4-dioxane solutions, followed by PEG extraction using deionized (DI) water. We have used an I-optimal design of experiments (DoE) and the response surface analysis (JMP® software) to relate three responses (scaffold thickness, porosity, and modulus) to the four experimental factors affecting the scaffold macro/microstructures (e.g., PEG strand diameter, PLGA concentration, nHA content, and TIPS temperature). Our results indicated that a PEG strand diameter of $\sim 380 \mu \mathrm{m}$, a PLGA concentration of $\sim 10 \% \mathrm{w} / \mathrm{v}$, a nHA content of $\sim 10 \% \mathrm{w} / \mathrm{w}$, and a TIPS temperature around $-10^{\circ} \mathrm{C}$ could generate scaffolds with a porosity of $\sim 90 \%$ and a modulus exceeding $4 \mathrm{MPa}$. This paper presents the steps for the I-optimal design of these scaffolds and reports on their macro/microstructures, characterized using scanning electron microscopy (SEM) and micro-computed tomography (micro-CT).
\end{abstract}

\footnotetext{
*Corresponding author: Azizeh-Mitra (Amy) Yousefi; Phone: 513-529-0766; Fax: 513-529-0761; yousefiam@ MiamiOH.edu; Address: 650 E High Street, Oxford, OH 45056.

Supporting Information. The DSC thermogram for PEG showing its melting peak temperature

Conflict of Interest Disclosure

The authors declare no competing financial interest.
} 


\section{Keywords}

3D plotting; additive manufacturing; bone tissue engineering; design of experiments (DoE); macro/microporous scaffolds; thermally induced phase separation

\section{Introduction}

Worldwide, bone fractures caused by osteoporosis are a major cause of suffering in the elderly population, and affect approximately one woman in three and one man in five over the age of 50 years. ${ }^{1}$ In the United States alone, over 1 million surgical procedures are performed annually that involve bone grafting, fracture repair, or the partial excision of bone. ${ }^{2}$ While bone grafts and substitutes are used in millions of operations worldwide, ${ }^{3}$ these therapies have limitations due to the risk of body's immune response, disease transfer, infection, or stress shielding. ${ }^{3,4}$ In critical size bone defects (nonunions), which contributes to $10 \%$ of bone fractures, ${ }^{5}$ the defect size is greater than the healing capacity of bone tissue, and therefore, fibrous connective tissue becomes dominant in the defect site. ${ }^{6}$

Tissue engineering is a relatively new alternative to current surgical procedures, and often involves the use of porous 3D scaffolds to serve as a temporary support and aid in tissue repair and regeneration. ${ }^{7-9}$ In particular, it is often hypothesized that 3D scaffolds with chemical compositions, biological, and mechanical properties mimicking the host bone would be more desirable, ${ }^{10-12}$ because such a design could stimulate the patient's body to repair the bone defect without the need for bone grafts. While the surface chemistry and topography affect cell adhesion and morphology, ${ }^{13,14}$ the $3 \mathrm{D}$ architecture of a porous scaffold regulates the transport of oxygen and nutrients and affects cell migration and osteogenesis. ${ }^{15,16}$ In particular, there is a great interest in 3D scaffolds with well-defined internal architectures and nanoscale morphologies, mimicking the extracellular matrix (ECM) of biological tissues. ${ }^{17,18}$ In light of this, scaffold design for bone tissue engineering is a booming domain and aims to promote cell attachment, proliferation, osteogenic differentiation, and bone matrix deposition. ${ }^{16,19,20}$

Poly(lactic-co-glycolic acid) (PLGA) has been widely used as a scaffold material for tissue engineering. This polymer offers ease of processing with a variety of conventional scaffold fabrication techniques and additive manufacturing (AM). PLGA is an amorphous polymer with a glass transition temperature of $\sim 50^{\circ} \mathrm{C} .{ }^{21} \mathrm{Hence}$, it can be dissolved at relatively low temperatures in common solvents used in processing of biomaterials, such as 14,dioxane ${ }^{22-24}$ and 1,1,1,3,3,3-hexafluoro-2-propanol (HFP). ${ }^{4,25,26}$ In particular, the freezing point of 1,4-dioxane is close to ambient temperature $\left(\sim 11.8^{\circ} \mathrm{C}\right)$, which makes it convenient for thermally induced phase separation (TIPS). The TIPS method is a desirable conventional technique for scaffold fabrication, as it is capable of generating highly porous scaffolds with an interconnected pore network. ${ }^{24,27}$ It has been reported that the cooling (quenching) temperature and rate, polymer concentration, polymer crystallinity, and the presence of ceramic powders can be used to manipulate and control the scaffold pore size, pore geometry, and interconnectivity. ${ }^{24,28}$ 
The limitation in the transport of oxygen, nutrients, and metabolic waste products is considered as one of the greatest challenges in the development of bioengineered bone of clinically relevant size.$^{29}$ In our previous study, we developed macro/microporous scaffolds made of PLGA using a hybrid technique that combined an extrusion-based additive manufacturing (AM), i.e., 3D-plotting (3DP), and TIPS method. ${ }^{27}$ The orthogonallyinterconnected channels produced by 3DP can provide an ideal environment to guide bone ingrowth, while facilitating the transport of oxygen and nutrients. The matrix surrounding these channels was composed of micropores generated by the TIPS method, allowing the control of pore size and morphology by manipulating the TIPS process parameters and scaffold composition. We have reported the potential of these scaffolds for supporting the growth of MC3T3-E1 cells in vitro. ${ }^{27}$

Most bones in the human body have $\sim 60-70 \%$ mineral/dry weight, ${ }^{30}$ which is primarily composed of nanometer-size hydroxyapatite (HA). The nanohydroxyapatite (nHA) in native bone is an important factor that affects the mechanical properties of the bone tissue. ${ }^{31,32}$ Therefore, many studies have incorporated nanoparticles or nanofibers into 3D scaffolds to mimic the extracellular matrix of bone tissue and to enhance the mechanical properties of the scaffolds. ${ }^{33-36}$ In addition, micro/nanoscale interactions with extracellular matrix (ECM) components of the bone tissue can influence stem cell behaviors. ${ }^{18,33}$ Hence, 3D scaffolds with nanoscale surface topographies and macro/microscale gradient structures, combined with biological domains, are highly sought in bone tissue engineering. ${ }^{11,17,37}$ In light of this, the evaluation of the biological function of gradient-based and hierarchical 3D scaffolds has been the subject of many recent studies. ${ }^{38-43}$

There is a widespread use of response surface designs whenever there is a need for deriving a relationship between a response and a set of experimental factors, and the process development and optimization in many industries have extensively relied on the design of experiments (DoE) ${ }^{44}$ However, a high number of experimental factors can make a completely randomized design (CRD) quite challenging, due to the requirement to perform a high number of experimental runs for a full factorial design. An I-optimal design would reduce the required number of runs to a fraction of the full factorial experiment. ${ }^{45} \mathrm{In}$ response surface designs, it is also a common practice to disregard certain high-order interactions and emphasize the main effects and low-order interactions.

Maximizing the compressive modulus of a 3D scaffold is often desirable in bone tissue engineering. However, this practice should take into consideration the requirement for a highly porous network for cell seeding/growth. This can be achieved by imposing a lowerlimit constraint on the scaffold porosity. The goal of this study was to target a scaffold modulus exceeding $5 \mathrm{MPa}$ while maintaining a porosity over $85 \%$. Our approach was to manipulate the four experimental factors in the fabrication of our hierarchical scaffolds, namely the diameter of the PEG strands, PLGA concentration, nHA content, and TIPS temperature. Upon the construction of a response surface in the target design region, a second-order regression model for each response (i.e., thickness, porosity and modulus) will lead to the relationships between the factors and responses. ${ }^{4,45}$ 
This paper presents an I-optimal design of experiments (DoE) to optimize the properties of our new hierarchical 3D scaffolds made of PLGA and nHA, or PLGA alone. Our experimental factors included three main parameters affecting the scaffold architecture in the TIPS method (namely, the PLGA concentration, nHA content, and the TIPS temperature), while investigating the role of the macrochannel diameter on the porosity and modulus of our 3D scaffolds. The I-optimal design and the response surface analysis (JMP® software) enabled us to find the relationships between the four experimental factors and three responses (scaffold thickness, porosity, and modulus) in order to maximize the scaffold modulus while keeping the porosity over $85 \%$. The produced scaffolds were characterized by scanning electron microscopy (SEM), micro-computed tomography (micro-CT), and unconfined compression tests.

\section{Materials}

Polyethylene glycol (PEG, $\mathrm{M}_{\mathrm{w}}=35 \mathrm{kDa}$ ), 1,4-dioxane (ACS reagent, $\searrow 99.0 \%$ ), hydroxyapatite nanopowder (<200 nm particle size (BET), $₫ 9 \%$, synthetic), and ethanol (EtOH) were purchased from Sigma-Aldrich. Poly(lactic-co-glycolic acid) (PLGA, RESOMER LG 824 S; I.V. = 1.7-2.6 dl/g; with a 79:21-85:15 molar ratio of 1lactide:glycolide) was purchased from Evonik Biomaterials.

\section{Methods}

\subsection{I-optimal design of 3D scaffolds}

For scaffold design in this study, Table 1 shows the four experimental factors $\left(N_{F}=4\right.$, representing $X_{1}$ to $\left.X_{4}\right)$ and the three levels for each factor $\left(N_{L}=3\right.$, with, low, medium, and high, denoted by $L, M$, and $H$ ). While a completely randomized full factorial design would lead to $N_{L}^{N} F=3^{4}=81$ runs, the fractional factorial I-optimal design in this study generated a total of 18 runs. The factor levels used in the 18 experimental runs proposed by the JMP® software are listed in Table 2 . Note that five scaffold designs had no nHA (" 0 " listed five times under " $X_{3}$ ”). We have used an I-optimal design, as it minimizes the average prediction variance across the design space. ${ }^{44,45}$ A second-order regression model for response surface design takes the following form: ${ }^{45}$

$$
Y=\beta_{0}+\beta_{1} x_{1}+\beta_{2} x_{2}+\beta_{3} x_{3}+\beta_{4} x_{4}+\sum_{i=1}^{4} \beta_{i i} x_{i}^{2}+\sum_{i=1}^{4} \sum_{j>i}^{4} \beta_{i j} x_{i} x_{j}+\epsilon
$$

In this equation, $\beta_{0}-\beta_{4}$ are the regression coefficients associated with the first order predictors, $\beta_{i i}$ are the second order coefficients, and $\beta_{i j}$ are the interaction coefficients. The lower-case factors $x_{1}-x_{4}$ in Eq. 1 take the values of $-1,0$, and 1, according to the following relationships with the experimental factors in Table $1\left(X_{1}-X_{4}\right)$ :

$$
\begin{aligned}
& x_{1}=\left(X_{1}-380\right) / 80 \\
& x_{2}=\left(X_{2}-10\right) / 2
\end{aligned}
$$




$$
\begin{aligned}
& x_{3}=\left(X_{3}-10\right) / 10 \\
& x_{4}=\left(X_{4}+10\right) / 10
\end{aligned}
$$

As listed in Table 1, $X_{1}$ is the PEG strand diameter $(\mu \mathrm{m}), X_{2}$ is the PLGA concentration (\% w/v), $X_{3}$ is the nHA content ( $\left.\% \mathrm{w} / \mathrm{w}\right)$, and $X_{4}$ is the TIPS temperature $\left({ }^{\circ} \mathrm{C}\right)$. The results of the analysis carried out in the JMP® software was the optimal set of factors for optimizing our hierarchical 3D scaffolds.

\subsection{Differential scanning calorimetry (DSC)}

A TA Instruments Q2000 ${ }^{\mathrm{TM}}$ DSC instrument was used to measure the melting temperature of PEG. The sample was weighed ( $\sim 5.4 \mathrm{mg})$, placed inside the sample pan and sealed. Then, the sample was heated from ambient temperature $\left(20^{\circ} \mathrm{C}\right)$ to $200^{\circ} \mathrm{C}$ at a rate of $10^{\circ} \mathrm{C} / \mathrm{min}$. The rate of heat flow per unit mass (in $\mathrm{W} / \mathrm{g}$ ) was recorded, and then the slope of the heat flow versus temperature, representing the specific heat capacity in $\mathrm{J} / \mathrm{g} .{ }^{\circ} \mathrm{C}$, was plotted as a function of temperature to identify the melting temperature of PEG.

\subsection{D-plotting of the porous PEG constructs}

As shown in Fig. 1a, polyethylene glycol (PEG) was melt-processed using a 3D-Bioplotter (EnvisionTEC ${ }^{\mathrm{TM}}$, Germany) to produce the porous PEG constructs. The high-temperature dispensing cartridge of the 3D-Bioplotter was filled with PEG granules and kept at $115^{\circ} \mathrm{C}$ for $5 \mathrm{~min}$ to reach thermal equilibrium. After 3D-plotting of the bottom layer, the newlydeposited strands were perpendicular to those of the previous layer and formed a $0^{\circ} / 90^{\circ}$ strand structure. It is anticipated that orthogonally-interconnected channels guide bone ingrowth and cell migration, while facilitating the transport of oxygen and nutrients and vascularization within a large scaffold/tissue graft. ${ }^{46-48}$ The PEG constructs were eventually leached out using deionized (DI) water to generate interconnected macrochannels within our PLGA/nHA or PLGA scaffolds prepared using the TIPS method (see section 4.3).

Figure $1 \mathrm{~b}$ shows the geometrical parameters of a 3D-plotted construct. The strand diameter (D) reflects the diameter of the macrochannels in the final PLGA/nHA or PLGA scaffolds. In melt-extrusion additive manufacturing, the viscoelastic extrudate swell often leads to strand diameters (D) greater than the dispensing needle diameter $\left(D_{n}\right)$. On the other hand, the plotting arm has the opposite effect as it pulls on the deposited strand. Therefore, the combined effect of the extrudate swell and the plotting arm movement often leads to considerable variations in the strand diameter. ${ }^{49-51}$ We conducted a series of experiments to find the combinations of the needle inner diameter $\left(D_{n}\right)$, plotting speed $(V)$, and dispensing pressure (P) that can generate the target strand diameters of $300 \mu \mathrm{m}, 380 \mu \mathrm{m}$, and $460 \mu \mathrm{m}$. Table 3 shows the fine-tuned plotting speeds and pressures for producing the porous PEG constructs with the three target strand diameters. The needle inner diameters $\left(D_{n}\right)$ and the actual strand diameters (D) are also listed in Table 3. Scanning electron microscopy (SEM) was used to measure the actual strand diameters based on the top-view and cross-section images of the 3D-plotted PEG (see section 5.3). 
The slicing thickness, or the layer thickness (h), was chosen to be $20 \%$ smaller that the strand diameter (D). This was to generate some overlap between the successive layers and prevent the delamination of the 3D-plotted PEG. This layer overlap ratio is shown as ( $D-$ h)/ $D$ in Fig. 1b. The actual layer thickness was measured using SEM based on the crosssection images of the 3D-plotted PEG. Finally, the edge-to-edge distance between the strands (L) was set to $1000 \mu \mathrm{m}$ for all PEG constructs, to facilitate the infiltration of the PLGA/nHA or PLGA solution into the porous PEG network (see section 4.3). The target and actual layer thickness (h), as well as the edge-to-edge and center-to-center distances between the strands $(L$ and $L+D$ ), are listed in Table 3. Depending on the actual strand diameter, an overall thickness of $4-4.5 \mathrm{~mm}$ for the 3D-plotted constructs was attained by laying down $12-15$ layers of PEG. Bricks of $13-\mathrm{mm} \times 13-\mathrm{mm}$ were 3D-plotted at $115^{\circ} \mathrm{C}$. This temperature was selected based on the DSC measurement, and after some preliminary experiments that aimed at analyzing the processability of PEG.

\subsection{PLGA/nHA and PLGA Scaffold fabrication}

Figure 2 shows the schematics of scaffold fabrication using the 3DP-TIPS technique. First, PLGA granules were cryogenically ground using liquid nitrogen inside a model 6770 Freezer/Mill (SPEX® SamplePrep). After a precool time of $5 \mathrm{~min}$, the grinding was performed for 10 min inside a stainless steel grinding mill operating at 10 cycles per second. The ground PLGA was blended with nHA powder, when applicable $(0 \%, 10 \%$, and $20 \%$ w/w), inside a 50-ml beaker. Then, $6 \mathrm{ml}$ of 1,4-dioxane was added to the blend to prepare PLGA and PLGA/nHA solutions with the concentrations of $8 \% \mathrm{w} / \mathrm{v}, 10 \% \mathrm{w} / \mathrm{v}$, and $12 \% \mathrm{w} / \mathrm{v}$ (see Table 2).

The prepared mixture was heated for 2.5 hours at $60^{\circ} \mathrm{C}$ inside a water bath. The mixture was sonicated three times for $10 \mathrm{~min}$ at an amplitude of 20 using a model 50 Sonic Dismembrator $^{\mathrm{TM}}$ (Fisherbrand ${ }^{\mathrm{TM}}$ ). Each sonication lasted $10 \mathrm{~min}$ and was performed before placing the beaker in the water bath, in the middle of the 2.5-hour heating process, and after removing the beaker from the bath. Then, four 3D-plotted PEG constructs were placed sideby-side at the bottom of the beaker. The beaker was then covered using parafilm and placed inside a model ZP-16-1.5-H/AC ${ }^{\mathrm{TM}}$ environmental chamber (Cincinnati Sub-Zero ${ }^{\mathrm{TM}}$ ). An Erlenmeyer flask containing ethanol was transferred to the environmental chamber at the same time. The chamber was heated to $40^{\circ} \mathrm{C}$ at a rate of $2^{\circ} \mathrm{C} / \mathrm{min}$, held at this temperature for $5 \mathrm{~min}$, and then cooled down at a rate $1.5^{\circ} \mathrm{C} / \mathrm{min}$ to the target temperatures specified by the I-optimal design (see Table 2).

The solidified solution was kept at the target temperature for 90 min to induce phase separation, and then $\sim 40 \mathrm{ml}$ of ethanol was poured in the beaker to extract 1,4-dioxane. The beaker was maintained inside the chamber for an additional 43.5 hours to fully extract the solvent and produce micropores. Ethanol was refreshed one hour before the end of the freezing period, and then the chamber was heated up to $20^{\circ} \mathrm{C}$ at a rate $1.5^{\circ} \mathrm{C} / \mathrm{min}$. The scaffold was removed from the beaker, air-dried for $45 \mathrm{~min}$, and punched into 10-mm and 5$\mathrm{mm}$ diameter disks for porosity measurements and mechanical testing, respectively. Then, the scaffolds were placed inside porous biopsy meshes and washed at $40^{\circ} \mathrm{C}$ inside a DI water bath equipped with a stir-bar stirring at $150 \mathrm{rpm}$. The scaffolds were kept in the bath for 48 
hours to extract the embedded PEG constructs. The DI water was refreshed two hours before the end of the washing period. Finally, the scaffolds were quenched for 1 hour inside a $-80^{\circ} \mathrm{C}$ freezer, transferred to a 1-L FreeZone ${ }^{\mathrm{TM}}$ benchtop freeze-dryer (Labconco ${ }^{\mathrm{TM}}$ ), and freeze-dried for 3 days (see Fig. 2). The prepared scaffolds were kept inside a $4^{\circ} \mathrm{C}$ refrigerator until characterization.

\subsection{Transmission Electron Microscopy (TEM)}

The TEM image of nHA powder was generated using a $200 \mathrm{kV}$ Joel JEM-2100 ${ }^{\mathrm{TM}}$ analytical TEM/STEM with a Gatan Orius SC200D camera.

\subsection{Scanning electron microscopy (SEM)}

The samples were sputter-coated with $20 \mathrm{~nm}$ gold using Denton Desk II Sputter Unit and imaged using a Zeiss ${ }^{\mathrm{TM}}$ Supra 35V microscope. PLGA granules, the PLGA powder obtained after cryogenic grinding, the 3D-plotted PEG constructs, as well as the PLGA/nHA and PLGA scaffolds were analyzed by SEM at an accelerating voltage of $5 \mathrm{kV}$.

\subsection{Microcomputed tomography (micro-CT)}

A Siemens ${ }^{\mathrm{TM}}$ Inveon Tri-Modal Scanner operating at $80 \mathrm{kVp}, 500 \mu \mathrm{A}$, and $1300 \mathrm{~ms}$ exposure time was used to perform the micro-CT imaging. The data analysis was performed using the Inveon research workplace bone morphology tool software. Hydroxyapatite (HA) cylindrical phantoms were used for the calibration of the micro-CT scanner. Then, the following equation was derived to convert the Hounsfield units (HU) to $\mathrm{mg} H A / \mathrm{cm}^{3}$ :

$$
\frac{m g H A}{\mathrm{~cm}^{3}}=0.24(H U)+1.70
$$

\subsection{Porosity measurements}

The porosity of the PLGA/nHA and PLGA scaffolds was calculated using the following equation:

$$
\varphi=\frac{v_{a}-V_{t}}{V_{a}} \times 100
$$

where $V_{a}$ is the apparent volume of the punched scaffold, calculated based on its thickness and diameter, and $V_{t}$ represents the true volume of the scaffold. The latter can be related to the scaffold matrix density $\left(\rho_{m}\right)$ and scaffold mass $(\mathrm{m})$ using:

$$
V_{t}=m / \rho_{m}
$$

Hence, the scaffold density $(\rho)$ can be related to its porosity $(\varphi)$ as:

$$
\rho=\rho_{m}(1-\varphi)
$$

For each of the 18 PLGA/nHA and PLGA scaffolds, the matrix density $\left(\rho_{m}\right)$ in (8) and (9) was calculated using the rule of mixtures based on the factor level $X_{3}$ (see Table 2). 


$$
\rho_{m}=\rho_{P L G A}\left(1-\frac{X_{3}}{100}\right)+\rho_{n H A}\left(\frac{X_{3}}{100}\right)
$$

In this equation, $\rho_{P L G A}=1.3 \mathrm{~g} / \mathrm{cm}^{3}$ and $\rho_{n \mathrm{HA}}=3.16 \mathrm{~g} / \mathrm{cm}^{3}$ are the PLGA and nHA densities,${ }^{31}$ respectively. The porosity calculations were based on 15 independent measurements $(n=15)$.

\subsection{Mechanical characterization}

A single-tower compression device (model 3344, Instron ${ }^{\mathrm{TM}}$ ) equipped with a $100 \mathrm{~N}$ load cell was used to characterize the compressive modulus of the PLGA/nHA and PLGA scaffolds. The tests were performed at a displacement rate of $1 \mathrm{~mm} / \mathrm{min}$ under unconfined ramp compression using a preload of $0.1 \mathrm{~N}$. The modulus was calculated based on the slope of the stress vs. strain graph at a strain of 5\%. The reported modulus is the average of 3 independent measurements $(n=3)$.

\section{Results}

\subsection{Differential scanning calorimetry (DSC)}

The DSC thermogram for PEG showed an endothermic peak at $\sim 63^{\circ} \mathrm{C}$, representing its melting temperature (See Fig. S1, Supplementary Information). Although the melting endotherm ended at $\sim 70^{\circ} \mathrm{C}$, a higher temperature $\left(115^{\circ} \mathrm{C}\right)$ was used for 3D-plotting of PEG. As mentioned earlier, this was based on some preliminary experiments that aimed at analyzing the processability of PEG. A temperature of $115^{\circ} \mathrm{C}$ enabled a quicker thermal equilibrium inside the 3D-Bioplotter cartridge, while producing defect-free PEG strands at a broad range of dispensing pressures and plotting speeds.

\subsection{Transmission electron microscopy (TEM)}

Figure 3a shows the TEM image of the nHA powder. Looking at the scale bar, most of the grains in this nano-powder have a grain size below $100 \mathrm{~nm}$. This is highly desirable for osteogenic differentiation of mesenchymal stem cells in bone tissue engineering.

\subsection{Scanning electron microscopy (SEM)}

The SEM images in Fig. $3 \mathrm{~b}$ and $3 \mathrm{c}$ show the PLGA granules before cryogenic grinding (> $500 \mu \mathrm{m}$ in size $)$ and the PLGA powder after grinding ( $<50 \mu \mathrm{m}$ in size $)$, respectively. The grinding process appeared to be effective in producing a homogenous mixture of PLGA/nHA in 1,4-dioxane. This observation was further supported based on the micro-CT scanning results (see section 5.4). Figure $3 \mathrm{~d}$ shows the SEM image of a PEG granule (< $1000 \mu \mathrm{m}$ in size). The relatively small particle size of PEG was a potential factor in achieving quick thermal equilibrium inside the 3D-Bioplotter cartridge, prior to the fabrication of the porous PEG constructs.

The top-view SEM images of the 3D-plotted PEG constructs are compared in Fig. 4a, 4c, and $4 \mathrm{e}$. The top-view strand diameters $(D)$ show some variation in the zones where the strands touch the underlying layer. Hence, the measured top-view diameters listed in Table 3 
represent the strand diameter mid-way between these contact zones. Nevertheless, the SEM images in Fig. 4b, 4d, and 4f reveal uniform cross-sectional diameters $(D)$, distance between strands $(L)$, and layer thicknesses $(h)$. Overall, the SEM images in Fig. 4 and Table 3 indicate that the target strand diameters $(300 \mu \mathrm{m}, 380 \mu \mathrm{m}$, and $460 \mu \mathrm{m})$ have been attained, if the average strand diameter from the top-view and cross-section (side-view) is taken into consideration ( $\sim 290 \mu \mathrm{m}, \sim 388 \mu \mathrm{m}$, and $\sim 457 \mu \mathrm{m}$, respectively).

Figure 5 shows the SEM images of some PLGA/nHA and PLGA scaffolds prepared in this study. The top row shows the scaffold for run 13 (10\% PLGA and 10\% nHA), prepared at a TIPS temperature of $-10^{\circ} \mathrm{C}$ using a PEG strand diameter of $380 \mu \mathrm{m}$. The top-view image in Fig. 5a shows the macrochannels surrounded with a microporous PLGA/nHA matrix. The macroporous network is clearly visible in the cross-section image shown in Fig. 5b, which reveals well-defined macrochannels created after the extraction of 3D-plotted PEG with DI water. Figure $5 \mathrm{c}$ depicts the zoomed-in view of the microporous PLGA/nHA matrix created after the extraction of 1,4-dioxane with ethanol, where the size of micropores is ranging between $20-40 \mu \mathrm{m}$.

Looking at the SEM images of the scaffold for run 9 (Fig. 5d - 5f), it appears that reducing PLGA to $8 \% \mathrm{w} / \mathrm{v}$ and eliminating nHA affect the overall integrity of the macrochannels (cross-section, Fig. 5e). This is possibly due to a highly microporous PLGA network at a lower PLGA concentration, which could make the scaffold more susceptible to handlingrelated defects during the multiple steps involved in scaffold fabrication. The zoomed-in SEM image in Fig. 5f shows that the size of micropores are comparable to that of the scaffold in Fig. 5c $(20-40 \mu \mathrm{m})$, although the pore morphology is slightly different in Fig. $5 \mathrm{c}$ due to the presence of nHA.

The third row in Fig. 5 shows the scaffold for run 3 (10\% PLGA and 10\% nHA), prepared at a TIPS temperature of $-10^{\circ} \mathrm{C}$ using a PEG strand diameter of $300 \mu \mathrm{m}$. Again, the macrochannels are not as well defined, which could be attributed to the low strand diameters making PEG extraction and macrochannel formation less effective. The last two rows in Fig. 5 show the scaffolds prepared at a TIPS temperature of $0^{\circ} \mathrm{C}$ (run 18 and run 1, respectively) using a PEG strand diameter of $460 \mu \mathrm{m}$. Overall, the scaffold for run 18 shows some larger macrochannels compared to the previous scaffolds. However, the size of micropores is $<5$ $\mu \mathrm{m}$ while showing some sub-micron structural patterns (Fig. 51). The same observation holds for run 1 (Fig. 5o). It should be noted that the extractions of PEG highly depends on the diffusion of DI water through the microporous network. Therefore, the lack of well-defined macrochannels in run 18 and run 1 could be attributed to the dense PLGA/nHA and PLGA matrix surrounding the embedded PEG.

\subsection{Microcomputed tomography}

Figure 6 shows the micro-CT images of the scaffold for run 11 (10\% PLGA and 20\% nHA), prepared at a TIPS temperature of $-10^{\circ} \mathrm{C}$ using a PEG strand diameter of $380 \mu \mathrm{m}$. Looking at the color scale-bar, which represents the density of the scaffold matrix, the cross-section image in Fig. 6a seems to point to a uniform distribution of nHA in PLGA at this high nHA concentration. The presence of macrochannels is visible in the cross-sectional views of the scaffold shown in Fig. 6b and 6c. Again, the top view of the scaffold in Fig. 6d shows a 
relatively uniform density for the scaffold matrix. However, the bottom-view image in Fig. 6e reveals some nHA precipitation, identified by the bright color reflecting the upper end of the density scale-bar. The relatively high PLGA concentration of $10 \% \mathrm{w} / \mathrm{v}$ leads to a viscous solution that could affect the uniformity of nHA dispersion. Figure $6 \mathrm{f}$ shows the density distribution for the scaffold, where higher values of the CT unit (in HU) on the x-axis represent higher densities. While soft tissues and polymers are identified between -590 to $-370 \mathrm{HU}^{52}$, bone and hydroxyapatite often characterized with values exceeding $-17 \mathrm{HU} .{ }^{52}$ The histogram shows a peak at $-720 \mathrm{HU}$, a mean value of $-450 \mathrm{HU}$, and extends between -960 and $2360 \mathrm{HU}$. The latter corresponds to $\sim 570 \mathrm{mg} \mathrm{HA} / \mathrm{cm}^{3}$, according to the micro-CT calibration formula, while the section exceeding $-17 \mathrm{HU}$ appears to have a mean of $12 \mathrm{HU}$ $\left(\sim 4.6 \mathrm{mg} \mathrm{HA} / \mathrm{cm}^{3}\right)$.

\subsection{Scaffold density and porosity}

Table 4 lists the scaffold densities and porosities for the 18 experimental runs, calculated based on the thickness, diameter, and weight of the scaffold, as well as the densities of PLGA and nHA (Eq. 7 - 10). The scaffold thickness varied between $3.54-4.33 \mathrm{~mm}$, whereas the density and porosity varied between $0.09-0.19 \mathrm{~g} / \mathrm{cm}^{3}$ and $87-93 \%$, respectively. Figure $7 \mathrm{a}-7 \mathrm{c}$ show the scaffold thickness, density, and porosity, respectively, as a function of the run number. As expected, these results indicate that the formulations with higher PLGA concentrations generated denser scaffolds, although the porosity in all cases exceeded $87 \%$.

\subsection{Scaffold modulus}

The compressive modulus of the scaffolds in Table 4 showed a pronounced variability for the 18 runs $(0.37-5.16 \mathrm{MPa})$. Looking at the magnitude of the error bars in Figure $7 \mathrm{~d}$, there is a lack of statistical significance for most of these scaffolds. The scaffolds were highly porous and occasionally had nonuniform geometries that deviated from a cylinder. These factors considerably affected the reproducibility of the mechanical testing.

\subsection{Statistical analysis}

The experimental data in Fig. 7 were fitted to the regression model in Eq. 1, considering both the first order and second order terms, as well as the interaction effects. Some insignificant second order and interactions terms were discarded, and only the significant terms were retained and used in response predictions. The regression coefficients $\beta_{0}-\beta_{4}$, as well as the second order coefficients $\beta_{i i}$ and $\beta_{i j}$ in Eq. 1 are listed in Table 5. These coefficients were used to construct the response-factor plots shown in Fig. 8.

According to Fig. 8a, the scaffold thickness would be the lowest $(\sim 3.6 \mathrm{~mm})$ at a PEG strand diameter of $\sim 376 \mu \mathrm{m}$, a PLGA concentration of $\sim 10.1 \% \mathrm{w} / \mathrm{v}$, a nHA content of $10 \% \mathrm{w} / \mathrm{w}$, and a TIPS temperature of $-10.6^{\circ} \mathrm{C}$. These results also indicate that the effects of the last two factors on the scaffold thickness were minimal. On the other hand, the PEG strand diameter appeared to have a minimal effect on the porosity (Fig. 8b), whereas the overall effects of increasing the PLGA concentration and the TIPS temperature were to reduce the porosity. Nevertheless, increasing the nHA content somewhat increased the porosity of the scaffolds (Fig. 8b). Finally, the predictions suggested that the scaffold modulus would be the 
highest (> $4 \mathrm{MPa}$ ) at a PEG strand diameter of $\sim 376 \mu \mathrm{m}, \sim 10.1 \% \mathrm{w} / \mathrm{v}$ of PLGA, $10 \% \mathrm{w} / \mathrm{w}$ of $\mathrm{nHA}$, and a TIPS temperature of $-10.6^{\circ} \mathrm{C}$. If we take into consideration the significant figures of the experimental measurements, the results of JMP® software for the three responses can be summarized as a PEG strand diameter of $\sim 380 \mu \mathrm{m}$, a PLGA concentration of $\sim 10 \% \mathrm{w} / \mathrm{v}$, a nHA content of $10 \% \mathrm{w} / \mathrm{w}$, and a TIPS temperature around $-10^{\circ} \mathrm{C}$. This corresponds to the experimental factors used for producing the PLGA/nHA scaffold in run 13.

Figure 9 shows the quality of the fitted regression models by comparing the experimental and predicted responses. The experimental results and model predictions for the porosity show a strong agreement $\left(R^{2}=0.91\right)$, whereas the model predictions for the thickness and modulus show a moderate agreement with their respective experimental results $\left(\mathrm{R}^{2}=0.79\right.$ and $\mathrm{R}^{2}=0.80$ ).

\section{Discussion}

The size of scaffold-tissue constructs can be a limiting factor in the in vivo integration of a bioengineered bone graft. This is mainly due to the high metabolic activity of bone cells, which require a highly-efficient supply of oxygen and nutrients throughout a 3D porous scaffold. ${ }^{18,29}$ It is well established that scaffold pore size has a significant effect on the in vivo vascularization of tissue-engineered bone. According to recent studies, new bone formation in vivo requires scaffold pore sizes in the range of 300-400 $\mu \mathrm{m}$, above which capillaries have been observed in newly formed bone. ${ }^{16,53}$ Also, it has been reported that a pore size greater than $350 \mu \mathrm{m}$ can enhance cell migration and angiogenesis. ${ }^{53}$ Therefore, the scaffold architecture (e.g., the porosity, pore size, and pore interconnectivity) has a key role in the success of a bioengineered bone graft.

Hybrid fabrication techniques that combine additive manufacturing and phase separation have been investigated in several recent studies. ${ }^{17,54-57}$ Liu et al. ${ }^{56}$ used a multi-nozzle lowtemperature deposition system to produce scaffolds made of PLGA or PLGA/tricalcium phosphate (TCP). Solidification of 1,4-dioxane at a low temperature followed by freezedrying generated 3D scaffolds with hierarchical porous structures. Prasopthum et al. ${ }^{17}$ 3Dprinted a solution of poly(L-lactide) (PLLA) or PLLA/nHA in tetrahydrofuran (THF), and then extracted the solvent using ethanol/water mixture prior to freeze-drying the scaffolds. Munir et al. ${ }^{57}$ 3D-printed a paste made of polycaprolactone (PCL) in 1,4-dioxane onto a platform held at a temperature of $-40^{\circ} \mathrm{C}$. Microporous 3D structures were generated by directional freezing, followed by solvent sublimation during freeze-drying.

The hybrid technique used in our study does not require the direct deposition of the polymer/ solvent mixtures, and thereby reduces the risk of exposure to high concentrations of organic solvents during scaffold fabrication. The cell compatibility of our hybrid scaffolds produced using the 3DP-TIPS technique was investigated in our previous study, by assessing their ability to support the attachment and growth of the murine MC3T3-E1 cell line for up to 21 days. ${ }^{27}$ The interconnected macrochannels generated upon the extraction of the 3D-plotted PEG had dimensions exceeding $\sim 350 \mu \mathrm{m}$, and could serve as conduits for cell migration and vascularization within the scaffolds. These macrochannels also played a critical role in cell 
seeding, and thereby reduced the variability in cell attachment, viability, and proliferation seen in the TIPS-only scaffolds. A higher rate of cell proliferation was observed for the smaller macrochannel $(\sim 360 \mu \mathrm{m}$ vs. $\sim 490 \mu \mathrm{m}),{ }^{27}$ which appeared to support a curvaturedriven mechanism for new tissue formation by osteoblasts reported by others. ${ }^{58}$

The hierarchical organization of the native bone tissue is often mimicked by incorporating nanoscale features and nanomaterials into the architecture of 3D scaffolds. ${ }^{18,33}$ The commonly accepted definition of nanomaterials refers to those with feature sizes ranging between 1 and $100 \mathrm{~nm} .{ }^{33}$ The TEM images revealed that the nHA used in this study primarily had nanoparticles below $100 \mathrm{~nm}$ in size. In addition, the SEM images demonstrated the potential of the TIPS method in generating sub-micron surface topographies. This has been reported by others, indicating that the TIPS method can generate nanotextures and yield a surface roughness favoring cell attachment and protein adsorption. ${ }^{59}$

The pore morphology of the 3D scaffolds produced by the TIPS method can be controlled by manipulating the type of polymer and solvent used, cooling rate, polymer concentration, TIPS temperature, as well as the presence of inorganic additives. ${ }^{22-24}$ The present study reported the I-optimal design of hierarchical 3D scaffolds made of PLGA/nHA and PLGA alone. We used the response surface analysis to find the relationships between our three responses (scaffold thickness, porosity, and modulus) and the four experimental factors affecting the scaffold macro/microporous architecture (PEG strand diameter, PLGA concentration, nHA content, and TIPS temperature). According to the model predictions using the JMP® software (Fig. 8), the scaffold thickness only slightly varied with the TIPS temperature and the nHA content, whereas the diameter of the 3D-poltted PEG and the PLGA concentration had the most pronounced effects on the thickness (Fig. 8a). The buoyancy effect upon embedding the 3D-plotted PEG in polymer solution is more significant for the highest strand diameter $(460 \mu \mathrm{m})$. In other words, the bulkiest PEG network considerably raises the level of the polymer solution and directly affects the thickness of the produced scaffold.

The porosity of the 3D scaffolds dropped with increasing the PLGA concentration and the TIPS temperature (Fig. 8b). Looking at Fig. 8b, and comparing Fig. 5c and 5f, it appears that nHA had no detrimental effect on pore formation, possibly due to the nanometer size of nHA particles. Our results also suggested that the diameter of the macrochannels had a minimal effect on the scaffolds porosity, thereby indicating the dominant effect of micropores, produced by TIPS, on the overall porosity of the hierarchical scaffolds. Note that the presence of macrochannels in 3DP-TIPS scaffolds is expected to reduce the modulus of the hierarchical 3D scaffolds, when compared to the scaffolds produced by the conventional TIPS-only technique. ${ }^{27}$

Finally, a TIPS temperature around $-10^{\circ} \mathrm{C}$ maximized the modulus, while both PLGA concentration and nHA content somewhat contributed to increasing the scaffold modulus (Fig. 8c). Overall, our results indicated that the PEG strand diameter had no detrimental effect on the modulus of the PLGA and PLGA/nHA scaffolds. Given the high desire for macropores exceeding $350 \mu \mathrm{m}$, a PEG strand diameter of $380 \mu \mathrm{m}$ used in this study would 
be an attractive design option, as it generated a modulus exceeding $4 \mathrm{MPa}$ (Fig. $7 \mathrm{~d}$ and Fig. $8 c$ ) and a porosity of $\sim 90 \%$ (Fig. 7 c and Fig. 8 b).

The 3D scaffolds prepared in this study were intended to have micropores below $50 \mu \mathrm{m}$ in size (see Fig. 5). These micropores can facilitate the transport of oxygen and nutrients, while their small size would not negatively impact the scaffold modulus. When a polymer solution is rapidly quenched to a given TIPS temperature, the scaffolds made at a lower quenching temperature tend to have smaller pore sizes, which can be attributed to the high nucleation rate and low crystal growth rate of 1,4-dioxane at low quenching temperatures. ${ }^{23,24}$ At high quenching temperatures, the formation of large solvent crystals can lead to pore sizes exceeding $500 \mu \mathrm{m}$, depending on the type of polymer used. ${ }^{24}$ In this study, we used a ramp temperature of $1.5^{\circ} \mathrm{C} / \mathrm{min}$ to cool the PLGA/nHA solution to the target TIPS temperatures of $-20^{\circ} \mathrm{C},-10^{\circ} \mathrm{C}$, and $0^{\circ} \mathrm{C}$. This was meant to enable a uniform temperature across the polymer solution in order to generate a more uniform micropore size. Hence, the time it took for the solution to reach the target TIPS temperature had a pronounced effect on the micropore size of the PLGA/nHA and PLGA scaffolds (Fig. 5). Relatively large micropores within the range of $20-40 \mu \mathrm{m}$ were produced using a TIPS temperature of $-10^{\circ} \mathrm{C}$ (Fig. $5 \mathrm{c}$ and $5 \mathrm{f}$ ), as opposed to the micropores below $5 \mu \mathrm{m}$ in size observed at a TIPS temperature of $0^{\circ} \mathrm{C}$ (Fig. 51 and 5o). The large micropores facilitated the extraction of the embedded PEG, as it is evidenced by the interconnected macrochannels formed after PEG extraction (Fig. 5b and $5 \mathrm{e})$. We have recently shown that these interconnected macrochannels produced by the 3DPTIPS technique can play a key role in cell seeding, by reducing the variability in cell attachment, viability, and proliferation seen in the microporous scaffolds produced by the conventional TIPS method. ${ }^{27}$

A TIPS temperature of $0^{\circ} \mathrm{C}$ dropped the porosity of the scaffolds below 89\% (Fig 8b) and reduced the size of micropores below $5 \mu \mathrm{m}$ (Fig. 51). Therefore, the extraction of PEG strands was not efficient at this range of micropore size (Fig. 5k and 5n). As discussed earlier, the JMP ${ }^{\circledR}$ software recommended a TIPS temperature around $-10^{\circ} \mathrm{C}$ (Fig. 8). This TIPS temperature produced micropores in the range of $20-40 \mu \mathrm{m}$ (Fig. $5 \mathrm{c}$ and $5 \mathrm{f}$ ), generated a porosity of $\sim 90 \%$ (Fig. 8b), and maximized the scaffold modulus (Fig. 8c). Note that the small size of micropores is also attributed to the high PLGA concentrations used in this study, which was aimed to produce a relatively dense PLGA/nHA or PLGA matrix around the macrochannels. The reported range of micropore size in our study is consistent with the previous studies, as a reduction in the pore size is expected with increasing the polymer concentration. ${ }^{23,24}$

In this study, the maximum modulus was achieved in the upper zone of our design region for nHA content (i.e., $10-20 \%$ w/w in Fig. 8c). Examining higher nHA percentages could potentially improve the compressive modulus of our hierarchical PLGA/nHA scaffolds. Nevertheless, previous studies have reported that a nHA content above $20 \% \mathrm{w} / \mathrm{w}$ may reduce the modulus of PLGA/nHA composites in certain cases. ${ }^{60}$ For example, the experimental procedures used for adding ceramics to polymers may lead to the agglomeration of ceramic particles and affect the final properties of the composite. To overcome this shortcoming, dispersion of ceramic particles into a polymer solution, followed by solvent casting, has been proposed as a means of improving the polymer/ceramic interfaces. ${ }^{4,61}$ As such, the 
experimental procedure reported in this paper (i.e., utilizing a polymer solution followed by multiple sonication steps) may enable us to expand the design region to a high nHA content of $40 \% \mathrm{w} / \mathrm{w}$ in our future studies.

\section{Conclusions}

In bone tissue engineering, the pore size, porosity, and pore interconnectivity of 3D scaffolds have key roles in the in vivo success of bioengineered bone. This study reported the design and characterization of hierarchical macro/microporous scaffolds made of PLGA/nHA or PLGA alone. We used an I-optimal design and the response surface analysis to investigate the effects of the PEG strand diameter, PLGA concentration, nHA content, and TIPS temperature on the thickness, porosity, and modulus of the scaffolds. The diameter of macrochannels, produced upon the extraction of 3D-plotted PEG, had a minimal effect on the scaffold porosity, but had a pronounced effect on the modulus of the scaffolds. According to JMP $®$ software predictions, a PEG strand diameter of $~ 380 \mu \mathrm{m}$, a PLGA concentration of $\sim 10 \% \mathrm{w} / \mathrm{v}$, a nHA content of $10 \% \mathrm{w} / \mathrm{w}$, and a TIPS temperature around $-10^{\circ} \mathrm{C}$ can generate scaffolds with a porosity of $\sim 90 \%$ and a modulus exceeding $4 \mathrm{MPa}$ (i.e., run 13). Our future studies will test the hypothesis that the hierarchical PLGA/nHA scaffolds can be further optimized to maximize the osteogenic differentiation of mesenchymal stem cells (MSCs) and enhance bone formation. The presence of macrochannels is expected to facilitate the transport of oxygen, nutrients, and metabolic waste, while playing an important role in cell migration and angiogenesis upon in vivo implantation.

\section{Supplementary Material}

Refer to Web version on PubMed Central for supplementary material.

\section{Acknowledgements}

Research reported in this paper was supported by the National Institute of Arthritis and Musculoskeletal and Skin Diseases of the National Institutes of Health under Award Number 1R15AR066269-01A1. The content is solely the responsibility of the authors and does not necessarily represent the official views of the National Institutes of Health. In addition, A.M. Yousefi thanks the funds from the Ohio Board of Regents (OBR), the Ohio Third Frontier Program, and Miami University Office for the Advancement of Research and Scholarship (OARS) that partially supported this study. The authors also thank Conor Flavin, Katherine Wood, Luke Marot, Brian Malerick, Ben Storsved, Ben Marks, Mia Price, Jacob Hogg, Matthew Duley, Douglas Hart, and Laurie Edwards from Miami University, as well as Kathleen LaSance and Lisa Lemen from the University of Cincinnati for their assistance with this study.

\section{References}

(1). Johnell O; Kanis J An Estimate of Worldwide Prevalence and Disability Associated with Osteoporotic Fractures. Osteoporos. Int 2006, 17 (12), 1726-1733. 10.1007/s00198-006-0172-4. [PubMed: 16983459]

(2). Health and Nutrition. US Census Bureau Statistical Abstracts of the United States; Washington, DC, 2006.

(3). Brydone AS; Meek D; Maclaine S Bone Grafting, Orthopaedic Biomaterials, and the Clinical Need for Bone Engineering. Proc. Inst. Mech. Eng. Part H J. Eng. Med 2010, 224 (12), 13291343. 10.1243/09544119JEIM770. 
(4). Uth N; Mueller J; Smucker B; Yousefi AM Validation of Scaffold Design Optimization in Bone Tissue Engineering: Finite Element Modeling versus Designed Experiments. Biofabrication 2017, 9, 015023 10.1088/1758-5090/9/1/015023. [PubMed: 28222045]

(5). Cheng H; Chabok R; Guan X; Chawla A; Li Y; Khademhosseini A; Jang HL Synergistic Interplay between the Two Major Bone Minerals, Hydroxyapatite and Whitlockite Nanoparticles, for Osteogenic Differentiation of Mesenchymal Stem Cells. Acta Biomater. 2018, 69, 342-351. 10.1016/j.actbio.2018.01.016. [PubMed: 29366976]

(6). Liu Y; Wu G; de Groot K Biomimetic Coatings for Bone Tissue Engineering of Critical-Sized Defects. J.R. Soc. Interface 2010, 7 (May), S631-S647. [PubMed: 20484228]

(7). Giannitelli SM; Rainer A; Accoto D; De Porcellinis S; De-Juan-Pardo EM; Guglielmelli E; Trombetta M Optimization Approaches for the Design of Additively Manufactured Scaffolds In Tissue Engineering: Computer Modeling, Biofabrication and Cell Behavior; Fernandes RP, Bartolo JP, Eds.; Springer Netherlands: Dordrecht, 2014; pp 113-128. 10.1007/978-94-007-7073-7_6.

(8). Langer R; Vacanti J Advances in Tissue Engineering. J. Pediatr. Surg 2016, 51 (1), 8-12. 10.1016/ j.jpedsurg.2015.10.022. [PubMed: 26711689]

(9). Hutmacher DW Scaffolds in Tissue Engineering Bone and Cartilage. Biomaterials 2000, 21 (24), 2529-2543. [PubMed: 11071603]

(10). Williams JM; Adewunmi A; Schek RM; Flanagan CL; Krebsbach PH; Feinberg SE; Hollister SJ; Das S Bone Tissue Engineering Using Polycaprolactone Scaffolds Fabricated via Selective Laser Sintering. Biomaterials 2005, 26 (23), 4817-4827. 10.1016/j.biomaterials.2004.11.057. [PubMed: 15763261]

(11). Bittner SM; Guo JL; Melchiorri A; Mikos AG Three-Dimensional Printing of Multilayered Tissue Engineering Scaffolds. Mater. Today 2018,

(12). Moutos FT; Freed LE; Guilak F A Biomimetic Three-Dimensional Woven Composite Scaffold for Functional Tissue Engineering of Cartilage. Nat. Mater 2007, 6 (2), 162-167. 10.1038/ nmat1822. [PubMed: 17237789]

(13). Singhvi R; Kumar A; Lopez GP; Stephanopoulos GN; Wang DI; Whitesides GM; Ingber DE Engineering Cell Shape and Function. Science (80-.). 1994, 264 (5159), 696-698.

(14). Chen H; Huang X; Zhang M; Damanik F; Baker MB; Leferink A; Yuan H; Truckenmüller R; van Blitterswijk C; Moroni L Tailoring Surface Nanoroughness of Electrospun Scaffolds for Skeletal Tissue Engineering. Acta Biomater. 2017, 59, 82-93. [PubMed: 28690010]

(15). Zeltinger J; Sherwood JK; Graham DA; Müeller R; Griffith LG Effect of Pore Size and Void Fraction on Cellular Adhesion, Proliferation, and Matrix Deposition. 2001, 7 (5), 557-572.

(16). Karageorgiou V; Kaplan D Porosity of 3D Biomaterial Scaffolds and Osteogenesis. Biomaterials 2005, 26 (27), 5474-5491. 10.1016/j.biomaterials.2005.02.002. [PubMed: 15860204]

(17). Prasopthum A; Shakesheff KM; Yang J Direct Three-Dimensional Printing of Polymeric Scaffolds with Nanofibrous Topography. Biofabrication 2018, 10 (2), 25002 10.1088/1758-5090/ aaa15b.

(18). Yousefi AM; James PF; Akbarzadeh R; Subramanian A; Flavin C; Oudadesse H Prospect of Stem Cells in Bone Tissue Engineering: A Review. Stem Cells Int 2016, 2016 (Article ID 6180487), 13 pages.

(19). Hollister SJ Porous Scaffold Design for Tissue Engineering. Nat. Mater 2005, 4 (7), 518-524. 10.1038/nmat1421. [PubMed: 16003400]

(20). Ho-Shui-Ling A; Bolander J; Rustom LE; Johnson AW; Luyten FP; Picart C Bone Regeneration Strategies: Engineered Scaffolds, Bioactive Molecules and Stem Cells Current Stage and Future Perspectives. Biomaterials 2018, 180, 143-162. [PubMed: 30036727]

(21). Klose D; Siepmann F; Elkharraz K; Krenzlin S; Siepmann J How Porosity and Size Affect the Drug Release Mechanisms from PLGA-Based Microparticles. Int. J. Pharm 2006, 314 (2), 198 206. 10.1016/j.ijpharm.2005.07.031. [PubMed: 16504431]

(22). Akbarzadeh R; Yousefi AM Effects of Processing Parameters in Thermally Induced Phase Separation Technique on Porous Architecture of Scaffolds for Bone Tissue Engineering. J. Biomed. Mater. Res. B. Appl. Biomater 2014, 102 (6), 1304-1315. 10.1002/jbm.b.33101. [PubMed: 24425207] 
(23). Huang YX; Ren J; Chen C; Ren TB; Zhou XY Preparation and Properties of Poly(Lactide-CoGlycolide) (PLGA)/Nano-Hydroxyapatite (NHA) Scaffolds by Thermally Induced Phase Separation and Rabbit MSCs Culture on Scaffolds. J. Biomater. Appl 2008, 22 (5), 409-432. 10.1177/0885328207077632. [PubMed: 17494961]

(24). Zhang R; Ma PX Poly(Alpha-Hydroxyl Acids)/Hydroxyapatite Porous Composites for BoneTissue Engineering. I. Preparation and Morphology. J. Biomed. Mater. Res 1999, 44 (4), 446455. [PubMed: 10397949]

(25). Jose MV; Thomas V; Xu Y; Bellis S; Nyairo E; Dean D Aligned Bioactive Multi-Component Nanofibrous Nanocomposite Scaffolds for Bone Tissue Engineering. Macromol. Biosci 2010, 10 (4), 433-444. 10.1002/mabi.200900287. [PubMed: 20112236]

(26). Ngiam M; Liao S; Patil AJ; Cheng Z; Chan CK; Ramakrishna S The Fabrication of NanoHydroxyapatite on PLGA and PLGA/Collagen Nanofibrous Composite Scaffolds and Their Effects in Osteoblastic Behavior for Bone Tissue Engineering. Bone 2009, 45 (1), 4-16. 10.1016/ j.bone.2009.03.674. [PubMed: 19358900]

(27). Akbarzadeh R; Minton JA; Janney CS; Smith TA; James PF; Yousefi AM Hierarchical Polymeric Scaffolds Support the Growth of MC3T3-E1 Cells. J. Mater. Sci. Mater. Med 2015, 26 (2), 116127. 10.1007/s10856-015-5453-z. [PubMed: 25665851]

(28). Wang X-D; Shou J; Wong P; French DM; Gao W-Q Notch1-Expressing Cells Are Indispensable for Prostatic Branching Morphogenesis during Development and ReGrowth Following Castration and Androgen Replacement. J. Biol. Chem 2004, 279 (23), 24733-24744. 10.1074/ jbc.M401602200. [PubMed: 15028713]

(29). Grayson W; Bhumiratana S; Cannizzaro C; Vunjak-Novakovic G Bioreactor Cultivation of Functional Bone Grafts In Mesenchymal Stem Cell Assays and Applications; Vemuri M, Chase L, Rao M, Eds.; Humana Press, 2011; p 698:231-241.

(30). Boskey AL Bone Composition: Relationship to Bone Fragility and Antiosteoporotic Drug Effects. Bonekey Rep. 2013, 2 (December), 1-11. 10.1038/bonekey.2013.181.

(31). Wei G; Ma PX Structure and Properties of Nano-Hydroxyapatite/Polymer Composite Scaffolds for Bone Tissue Engineering. Biomaterials 2004, 25 (19), 4749-4757. 10.1016/j.biomaterials. 2003.12.005. [PubMed: 15120521]

(32). McMahon RE; Wang L; Skoracki R; Mathur AB Development of Nanomaterials for Bone Repair and Regeneration. J. Biomed. Mater. Res. B. Appl. Biomater 2013, 101 (2), 387-397. 10.1002/ jbm.b.32823. [PubMed: 23281143]

(33). Gong T; Xie J; Liao J; Zhang T; Lin S; Lin Y Nanomaterials and Bone Regeneration. Bone Res. 2015, 3 (August), 15029:1-7. 10.1038/boneres.2015.29. [PubMed: 26558141]

(34). Uth N; Mueller J; Smucker B; Yousefi A-M Validation of Scaffold Design Optimization in Bone Tissue Engineering: Finite Element Modeling versus Designed Experiments. Biofabrication 2017, 9 (1). 10.1088/1758-5090/9/1/015023.

(35). Zhang J; Liu H; Ding J-X; Wu J; Zhuang X-L; Chen X-S; Wang J-C; Yin J-B; Li Z-M HighPressure Compression-Molded Porous Resorbable Polymer/Hydroxyapatite Composite Scaffold for Cranial Bone Regeneration. ACS Biomater. Sci. Eng 2016, 2 (9), 1471-1482. 10.1021/ acsbiomaterials.6b00202.

(36). Manoukian OS; Aravamudhan A; Lee P; Arul MR; Yu X; Rudraiah S; Kumbar SG Spiral Layerby-Layer Micro-Nanostructured Scaffolds for Bone Tissue Engineering. ACS Biomater. Sci. Eng 2018, 4 (6), 2181-2192. 10.1021/acsbiomaterials.8b00393. [PubMed: 30976659]

(37). Yousefi AM; Hoque ME; Prasad RGSV; Uth N Current Strategies in Multiphasic Scaffold Design for Osteochondral Tissue Engineering: A Review. J. Biomed. Mater. Res. Part A 2015, 103 (7), 2460-2481. 10.1002/jbm.a.35356.

(38). Yousefi A-M; Hoque ME; Prasad RGSV; Uth N Current Strategies in Multiphasic Scaffold Design for Osteochondral Tissue Engineering: A Review. J. Biomed. Mater. Res. - Part A 2015, 103 (7). 10.1002/jbm.a.35356.

(39). Zhou C; Yang K; Wang K; Pei X; Dong Z; Hong Y; Zhang X Combination of Fused Deposition Modeling and Gas Foaming Technique to Fabricated Hierarchical Macro/Microporous Polymer Scaffolds. Mater. Des 2016, 109, 415-424. 
(40). Song P; Zhou C; Fan H; Zhang B; Pei X; Fan Y; Jiang Q; Bao R; Yang Q; Dong Z; Zhang X Novel 3D Porous Biocomposite Scaffolds Fabricated by Fused Deposition Modeling and Gas Foaming Combined Technology. Compos. Part B Eng. 2018, 152, 151-159.

(41). Zhang XP and M. L and Z. B and S. J and S. Y and F. Y and G. Z and Z. C and X. Creating Hierarchical Porosity Hydroxyapatite Scaffolds with Osteoinduction by Three-Dimensional Printing and Microwave Sintering. Biofabrication 2017, 9 (4), 45008.

(42). Ghannadian P; Moxley JW; Machado de Paula MM; Lobo AO; Webster TJ Micro-Nanofibrillar Polycaprolactone Scaffolds as Translatable Osteoconductive Grafts for the Treatment of Musculoskeletal Defects without Infection. ACS Appl. Bio Mater 2018 10.1021/acsabm. $8 \mathrm{~b} 00453$.

(43). Wang J; Loye AM; Ketkaew J; Schroers J; Kyriakides TR Hierarchical Micro- and Nanopatterning of Metallic Glass to Engineer Cellular Responses. ACS Appl. Bio Mater. 2018, 1 (1), 51-58. 10.1021/acsabm.8b00007.

(44). Sambo F; Borrotti M; Mylona K A Coordinate-Exchange Two-Phase Local Search Algorithm for the D- and I-Optimal Designs of Split-Plot Experiments. Comput. Stat. Data Anal 2014, 71, 1193-1207. 10.1016/j.csda.2013.03.015.

(45). Myers Raymond H., Montgomery Douglas C., A.-C. CM Response Surface Methodology: Process and Product Optimization Using Designed Experiments; Edition, 4th, Ed.; Wiley: New York, 2016.

(46). Nazhat SN; Neel EAA; Kidane A; Ahmed I; Hope C; Kershaw M; Lee PD; Stride E; Saffari N; Knowles JC; Brown RA Controlled Microchannelling in Dense Collagen Scaffolds by Soluble Phosphate Glass Fibers. Biomacromolecules 2007, 8 (2), 543-551. 10.1021/bm060715f. [PubMed: 17291078]

(47). Lee J-Y; Choi B; Wu B; Lee M Customized Biomimetic Scaffolds Created by Indirect ThreeDimensional Printing for Tissue Engineering. Biofabrication. 122013 10.1088/1758-5082/5/4/045003.

(48). Yousefi A-M; Gauvin C; Sun L; DiRaddo RW; Fernandas J Design and Fabrication of 3D-Plotted Polymeric Scaffolds in Functional Tissue Engineering. Polym. Eng. Sci 2007, 47 (5). 10.1002/ pen.20732.

(49). Yousefi A-M; Smucker B; Naber A; Wyrick C; Bennett K; Szekely S; Focke C; Wood KA Controlling the Extrudate Swell in Melt Extrusion Additive Manufacturing of 3D Scaffolds: A Designed Experiment. J. Biomater. Sci. Polym. Ed 2018, 5063, 1-23. 10.1080/09205063.2017.1409022.

(50). Heller BP; Smith DE; Jack DA Effects of Extrudate Swell and Nozzle Geometry on Fiber Orientation in Fused Filament Fabrication Nozzle Flow. Addit. Manuf 2016, 12, 252-264. 10.1016/j.addma.2016.06.005.

(51). Turner BN; Gold SA; Turner BN; Gold SA A Review of Melt Extrusion Additive Manufacturing Processes: II. Materials, Dimensional Accuracy, and Surface Roughness. Rapid Prototyp. J 2015, 21 (3), 260-261. 10.1108/RPJ-02-2013-0017.

(52). Tuan HS; Hutmacher DW Application of Micro CT and Computation Modeling in Bone Tissue Engineering. Comput. Des 2005, 37, 1151-1161. 10.1016/j.cad.2005.02.006.

(53). Sun L; Parker ST; Syoji D; Wang X; Lewis JA; Kaplan DL Direct-Write Assembly of 3D Silk/ Hydroxyapatite Scaffolds for Bone Co-Cultures. Adv Heal. Mater 2012, 1, 729-735.

(54). Xiong Z; Yan Y; Wang S; Zhang R; Zhang C Fabrication of Porous Scaffolds for Bone Tissue Engineering via Low-Temperature Deposition. Scr. Mater 2002, 46 (11), 771-776. 10.1016/ S1359-6462(02)00071-4.

(55). Liu W; Wang D; Huang J; Wei Y; Xiong J; Zhu W; Duan L Low-Temperature Deposition Manufacturing: A Novel and Promising Rapid Prototyping Technology for the Fabrication of Tissue-Engineered Scaffold. Mater. Sci. Eng. C 2017, 70, 976-982. 10.1016/j.msec.2016.04.014.

(56). Liu L; Xiong Z; Yan Y; Zhang R; Wang X; Jin L Multinozzle Low-Temperature Deposition System for Construction of Gradient Tissue Engineering Scaffolds. J. Biomed. Mater. Res. - Part B Appl. Biomater 2008, 88 (1), 254-263. 10.1002/jbm.b.31176. 
(57). Munir N; Larsen RS; Callanan A Fabrication of 3D Cryo-Printed Scaffolds Using LowTemperature Deposition Manufacturing for Cartilage Tissue Engineering. Bioprinting 2018, e00033 10.1016/j.bprint.2018.e00033.

(58). Rumpler M; Woesz A; Dunlop JWC; van Dongen JT; Fratzl P The Effect of Geometry on ThreeDimensional Tissue Growth. J. R. Soc. Interface 2008, 5 (27), 1173-1180. 10.1098/rsif. 2008.0064. [PubMed: 18348957]

(59). Ng R; Zang R; Yang KK; Liu N; Yang S-T Three-Dimensional Fibrous Scaffolds with Microstructures and Nanotextures for Tissue Engineering. RSC Adv. 2012, 2 (27), 10110-10124.

(60). Wagoner Johnson AJ; Herschler BA A Review of the Mechanical Behavior of CaP and CaP/ Polymer Composites for Applications in Bone Replacement and Repair. Acta Biomater. 2011, 7 (1), 16-30. 10.1016/j.actbio.2010.07.012. [PubMed: 20655397]

(61). Mathieu LM; Bourban P-E; Månson J-AE Processing of Homogeneous Ceramic/Polymer Blends for Bioresorbable Composites. Compos. Sci. Technol 2006, 66 (11-12), 1606-1614. 


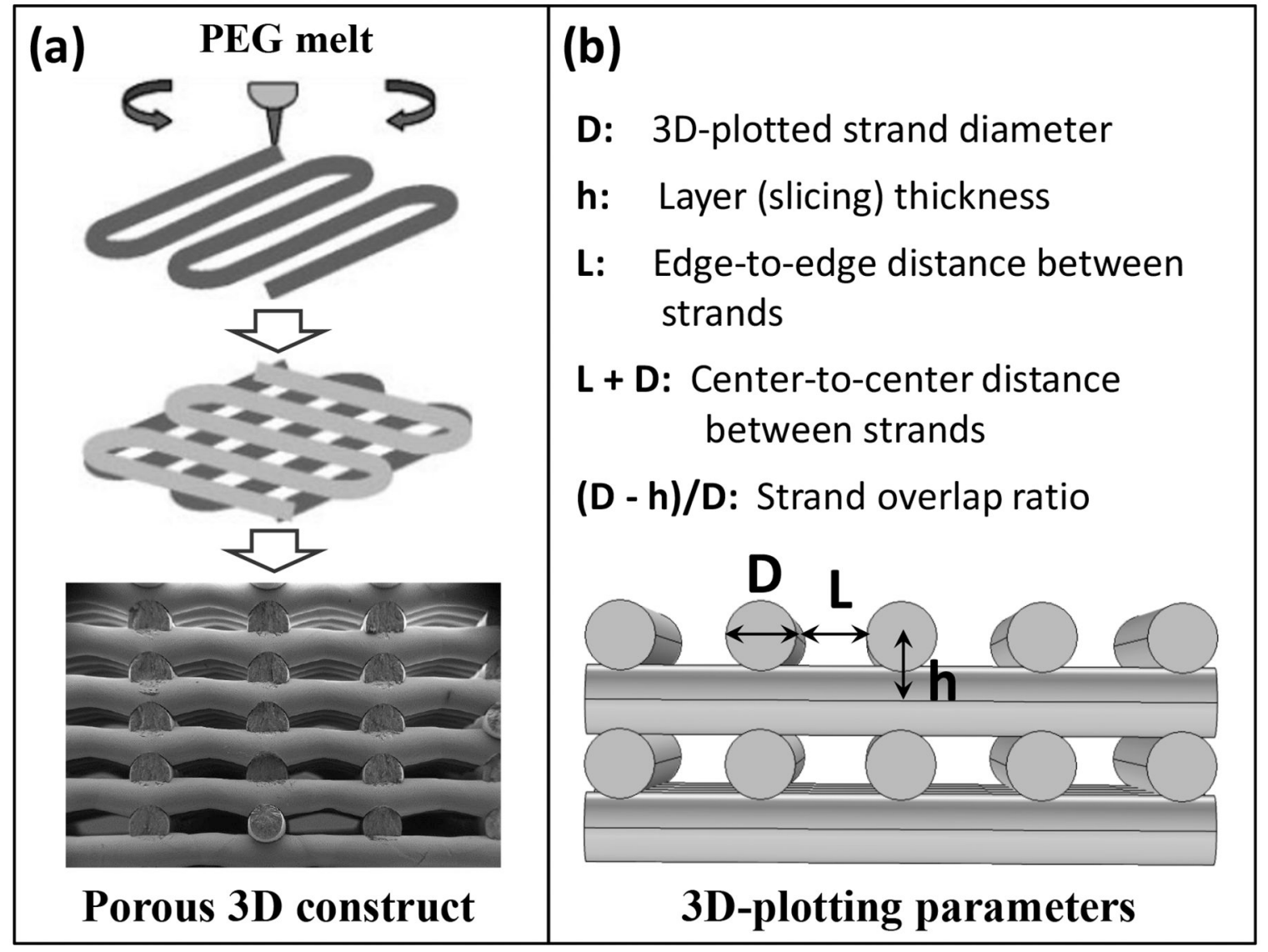

Figure 1.

(a) Schematics of the 3D-plotting used for melt processing of PEG, and (b) the description of the 3D-plotting parameters. Partially reproduced with permission from reference 48. Copyright 2007 John Wiley and Sons. 


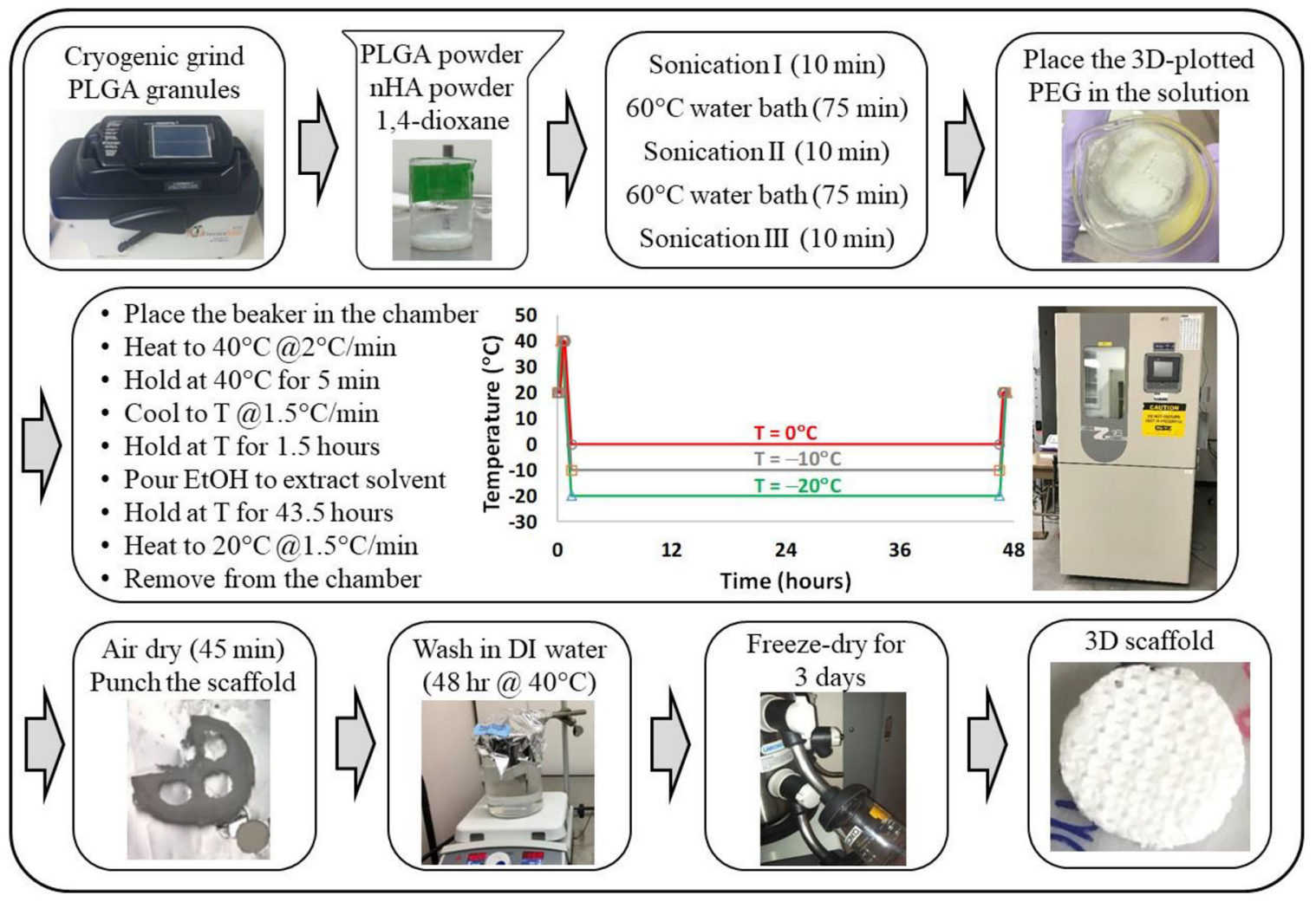

Figure 2.

Schematics of the scaffold fabrication process using the 3DP-TIPS technique. 

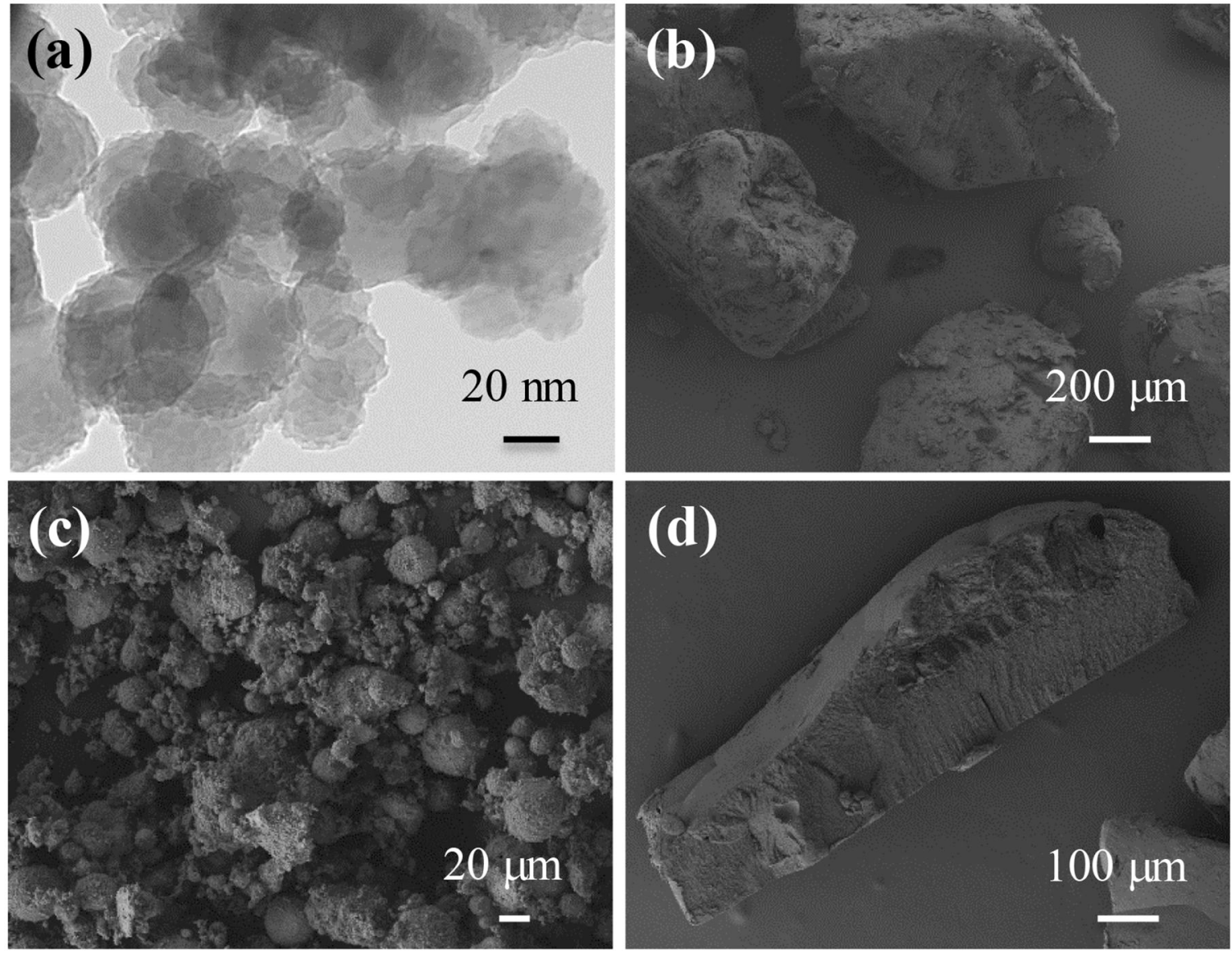

Figure 3.

Morphological characteristics of (a) nHA powder, (b) PLGA granules, (c) ground PLGA powder, and (d) PEG granule. Micrographs were created using TEM (a) and SEM (b-d). 

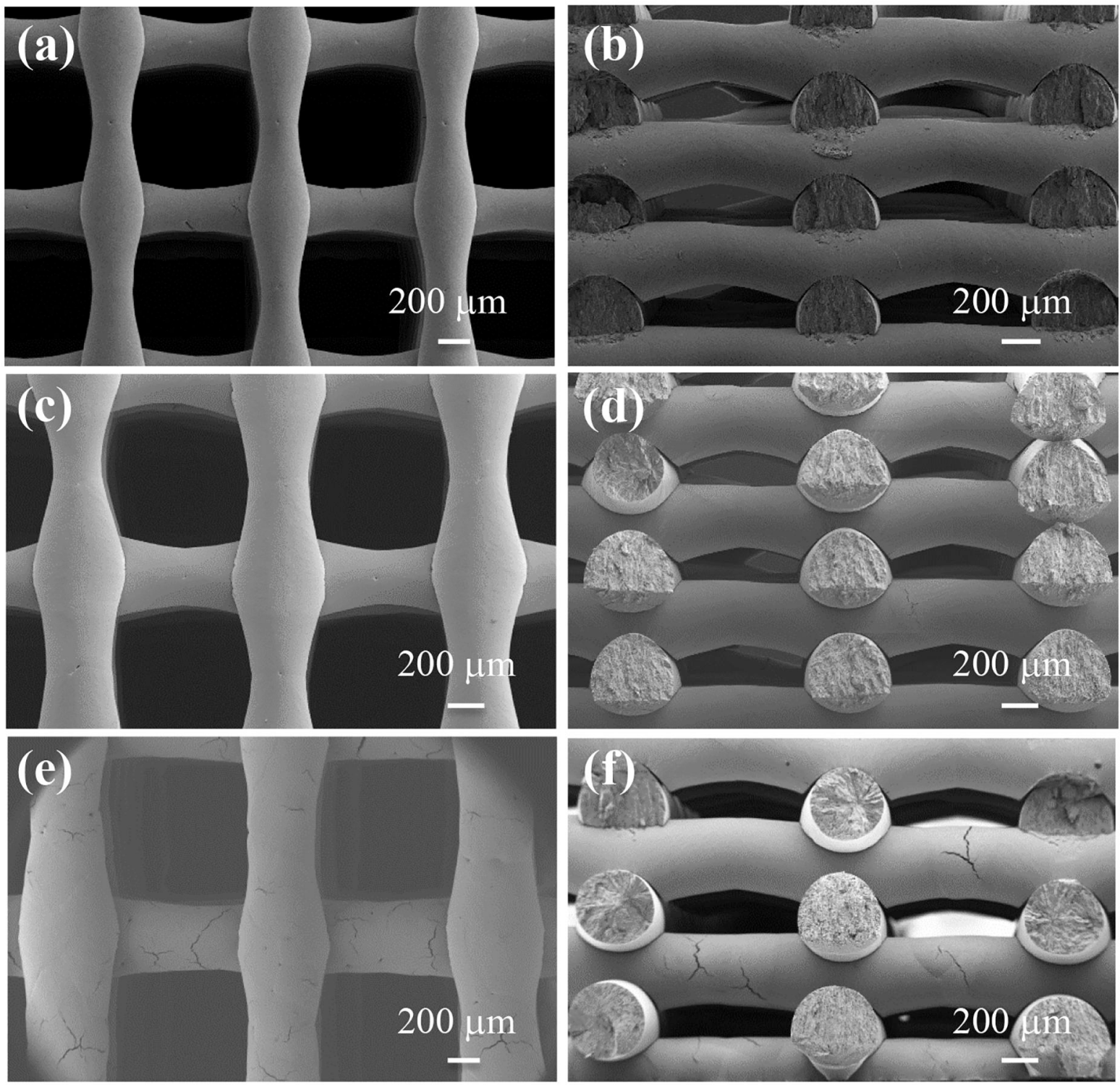

Figure 4.

The top view (left) and the cross-sectional view (right) of the 3D-plotted PEG constructs as seen by SEM. The three target strand diameters were $300 \mu \mathrm{m}$ (a \& b), $380 \mu \mathrm{m}$ (c \& d), and $460 \mu \mathrm{m}$ (e \& f). 


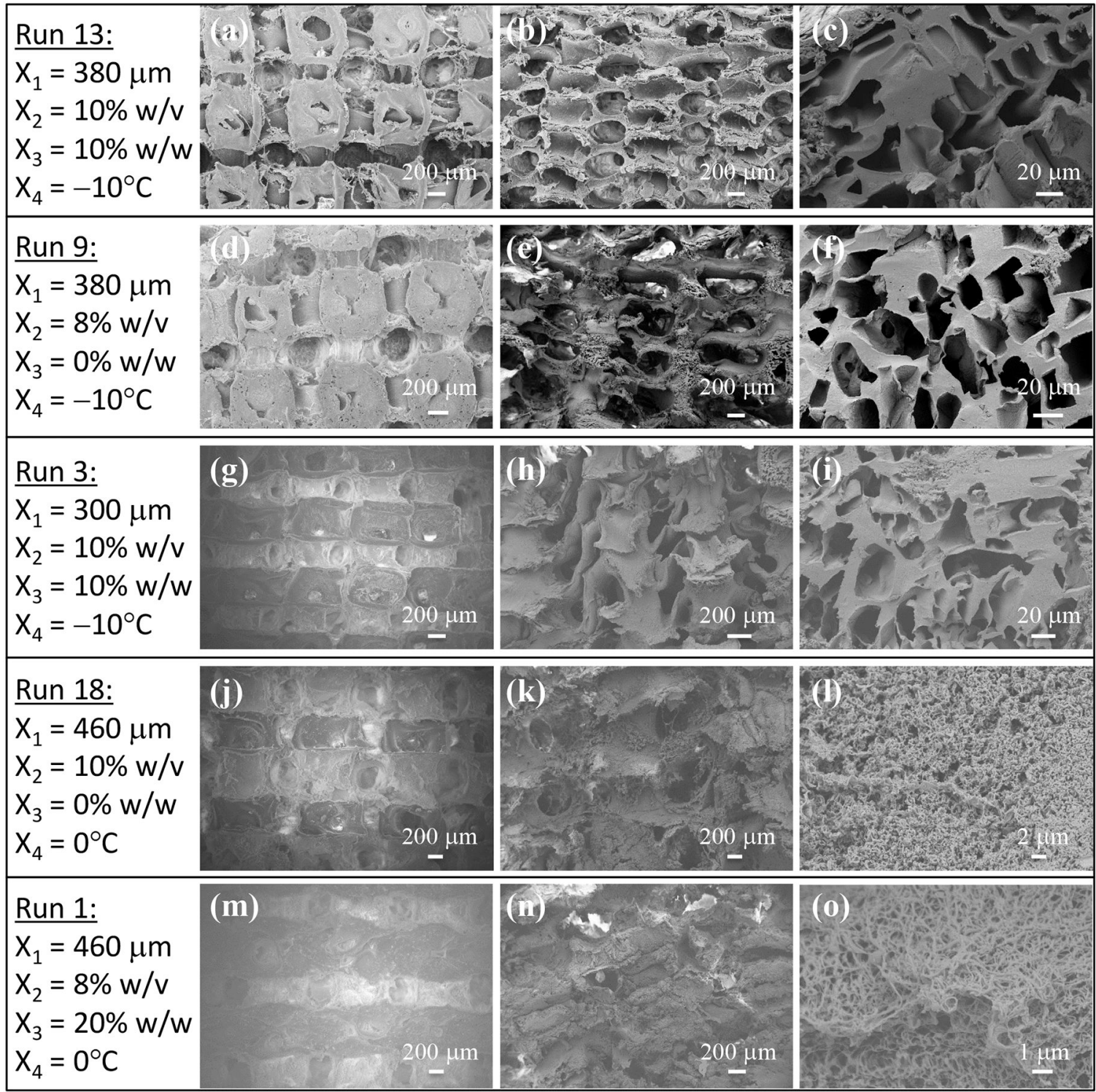

Figure 5.

The top-view (left) and the cross-sectional views (middle and right) of the PLGA/nHA and PLGA scaffolds as seen by SEM. These micrographs show the pore size range and overall structure of the scaffolds produced using the 3DP-TIPS technique; Run 13 (a-c), Run 9 (d-f), Run 3 (g-i), Run 18 (j-1), and Run 1 (m-o). 

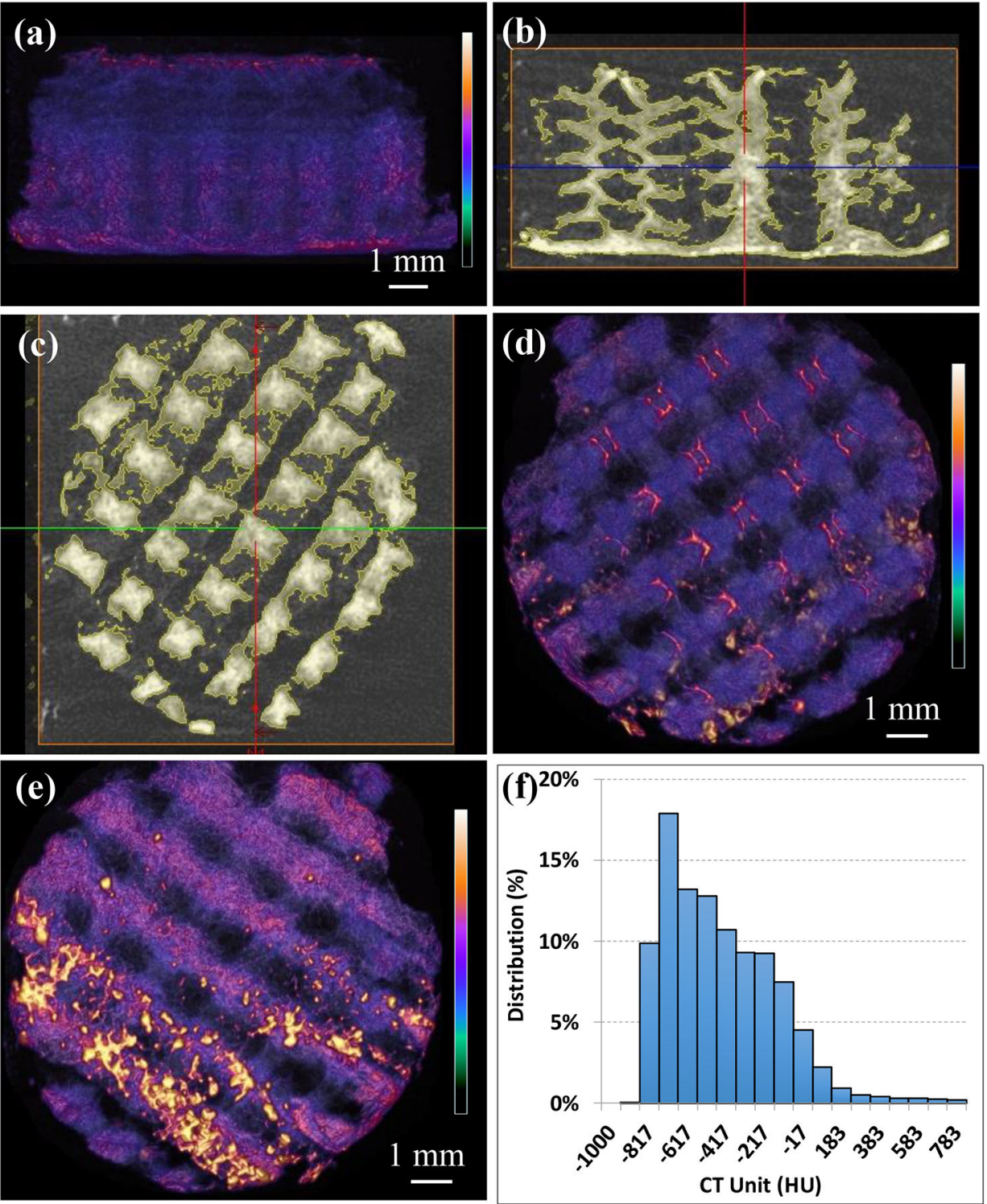

Figure 6.

The micro-CT images of a PLGA/nHA scaffold produced using the 3DP-TIPS technique (run 12); (a) side view, (b \& c) cross-sectional side- and top-views, (d) top view, (e) bottom view, and (f) the histogram showing the distribution of density in CT unit (HU). 

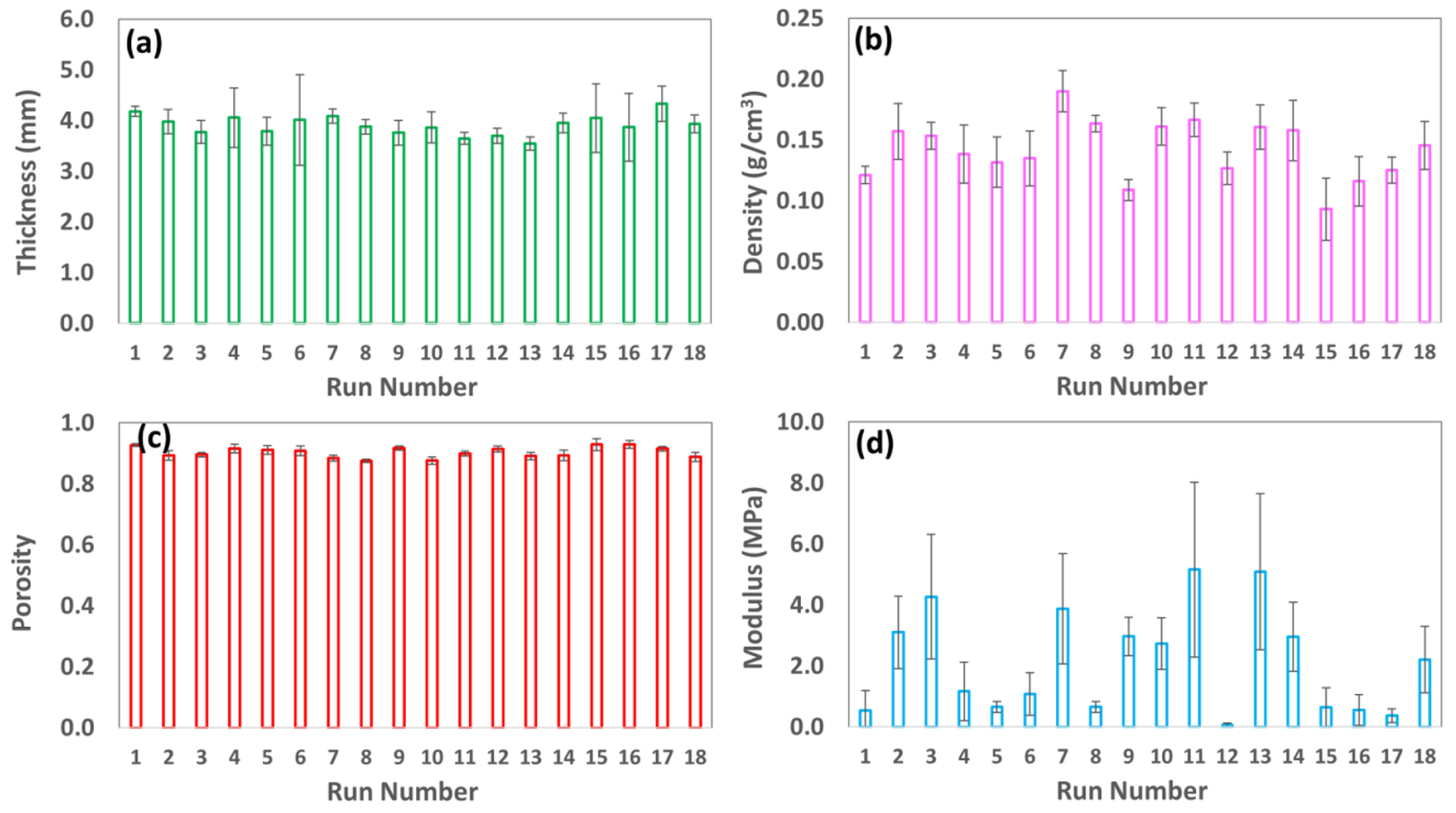

Figure 7.

The summary of the experimental measurements for the 18 DoE runs: (a) thickness, (b) density, (c) porosity, and (d) modulus of the scaffolds prepared using the 3DP-TIPS technique. 

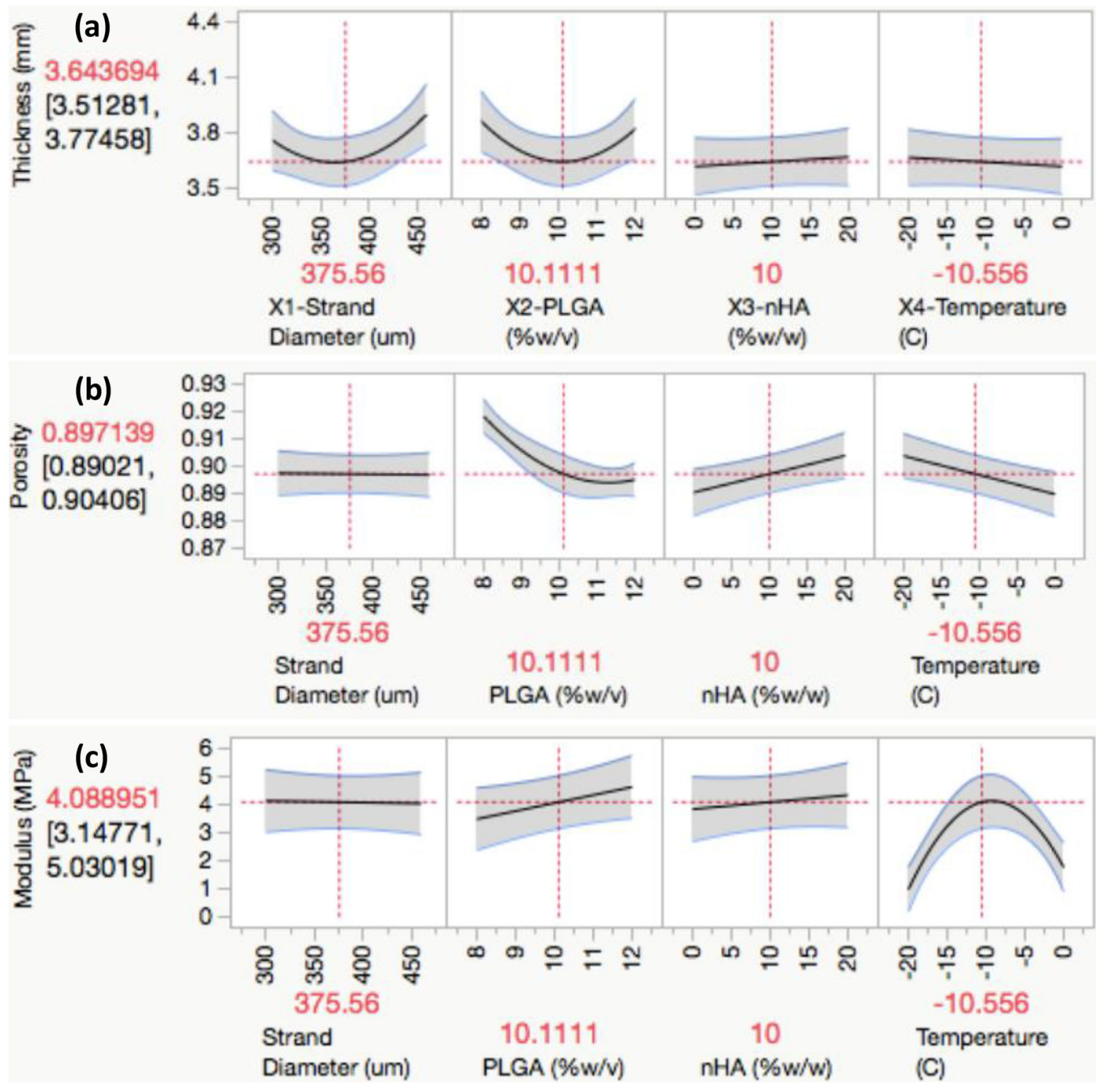

Figure 8.

The contour plots produced by the JMP® software showing the response surface analysis of (a) scaffold thickness, (b) scaffold porosity, and (c) scaffold modulus versus the four experimental factors (PEG strand diameter, PLGA\%, and nHA\%, and TIPS temperature). 

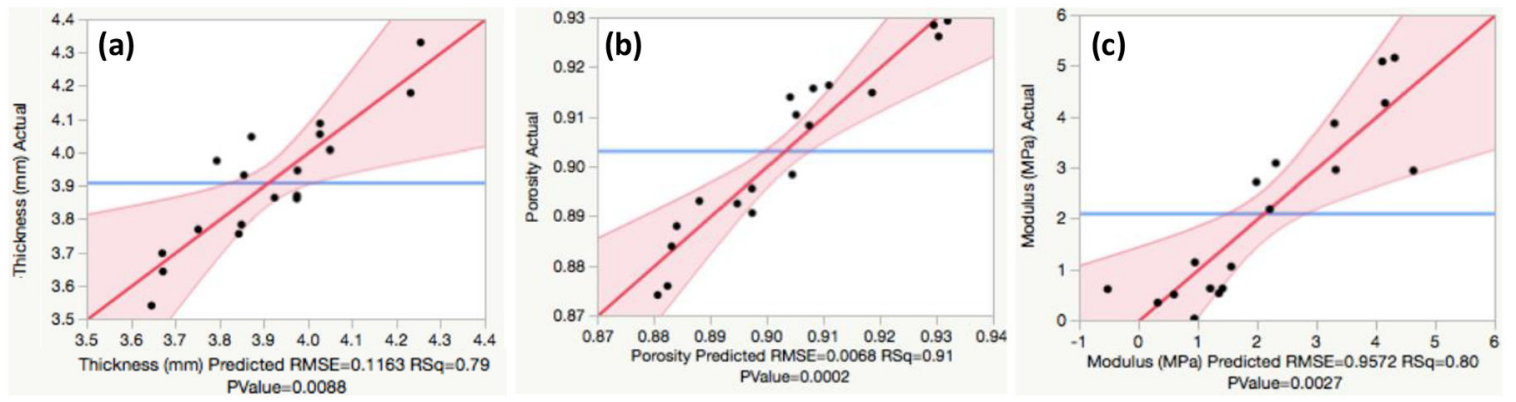

Figure 9.

Plots of the experimental versus predicted responses for the thickness (a), porosity (b), and modulus (c) of the scaffolds prepared using the 3DP-TIPS technique. 
Table 1.

The levels of the experimental factors investigated in this study.

\begin{tabular}{lccc}
\hline Factors & $\boldsymbol{L}$ & $\boldsymbol{M}$ & $\boldsymbol{H}$ \\
\hline Strand Diameter $\left(X_{1}\right)$ & $300 \mu \mathrm{m}$ & $380 \mu \mathrm{m}$ & $460 \mu \mathrm{m}$ \\
PLGA Concentration $\left(X_{2}\right)$ & $8 \% \mathrm{w} / \mathrm{v}$ & $10 \% \mathrm{w} / \mathrm{v}$ & $12 \% \mathrm{w} / \mathrm{v}$ \\
nHA Content $\left(X_{3}\right)$ & $0 \% \mathrm{w} / \mathrm{w}$ & $10 \% \mathrm{w} / \mathrm{w}$ & $20 \% \mathrm{w} / \mathrm{w}$ \\
Temperature $\left(X_{4}\right)$ & $-20^{\circ} \mathrm{C}$ & $-10^{\circ} \mathrm{C}$ & $0^{\circ} \mathrm{C}$ \\
\hline
\end{tabular}


Table 2.

The 18-run I-optimal design used for scaffold fabrication.

\begin{tabular}{ccccc}
\hline Run & $\boldsymbol{X}_{\mathbf{1}}(\boldsymbol{\mu m})$ & $\boldsymbol{X}_{\mathbf{2}}(\boldsymbol{\%} \mathbf{W} / \mathrm{V})$ & $\boldsymbol{X}_{\mathbf{3}}(\boldsymbol{\%} \mathbf{W} / \mathrm{W})$ & $\boldsymbol{X}_{\mathbf{4}}\left({ }^{\circ} \mathbf{C}\right)$ \\
\hline 1 & 460 & 8 & 20 & 0 \\
2 & 380 & 12 & 10 & 0 \\
3 & 300 & 10 & 10 & -10 \\
4 & 460 & 12 & 20 & -20 \\
5 & 300 & 8 & 10 & 0 \\
6 & 300 & 12 & 10 & -20 \\
7 & 300 & 12 & 20 & 0 \\
8 & 300 & 12 & 0 & 0 \\
9 & 380 & 8 & 0 & -10 \\
10 & 460 & 12 & 0 & -20 \\
11 & 380 & 10 & 20 & -10 \\
12 & 380 & 10 & 10 & -20 \\
13 & 380 & 10 & 10 & -10 \\
14 & 460 & 12 & 10 & -10 \\
15 & 300 & 8 & 0 & -20 \\
16 & 300 & 8 & 20 & -20 \\
17 & 460 & 8 & 10 & -20 \\
18 & 460 & 10 & 0 & 0 \\
\hline
\end{tabular}

를

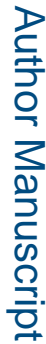

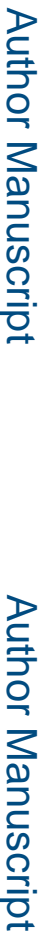

ACS Appl Bio Mater. Author manuscript; available in PMC 2020 January 15. 
Table 3.

3D-plotting parameters used in producing porous PEG constructs with the three target strand diameters.

\begin{tabular}{|c|c|c|c|c|c|c|c|c|c|c|c|}
\hline \multirow{2}{*}{$\begin{array}{c}\begin{array}{c}\text { Needle } \\
\text { Diameter }\end{array} \\
\begin{array}{c}(\mu \mathbf{n}) \\
D_{n}\end{array}\end{array}$} & \multirow{2}{*}{$\begin{array}{c}\begin{array}{c}\text { Plotting } \\
\text { Speed } \\
(\mathbf{m m} / \mathbf{s})\end{array} \\
\\
V\end{array}$} & \multirow{2}{*}{$\begin{array}{c}\text { Dispensing } \\
\text { Pressure } \\
\text { (bar) } \\
\\
\quad P\end{array}$} & \multirow{2}{*}{$\begin{array}{c}\text { Melt } \\
\text { Temp. } \\
\left({ }^{\circ} \mathbf{C}\right) \\
T_{m}\end{array}$} & \multirow{2}{*}{$\begin{array}{c}\text { Target } \\
\text { Strand } \\
\text { Diameter } \\
(\mu \mathrm{m})\end{array}$} & \multicolumn{2}{|c|}{$\begin{array}{l}\text { Actual Strand } \\
\text { Diameter }(\mu \mathrm{m})\end{array}$} & \multicolumn{2}{|c|}{$\begin{array}{l}\text { Layer (Slicing) } \\
\text { Thickness }(\mu \mathbf{m})\end{array}$} & \multicolumn{2}{|c|}{$\begin{array}{c}\text { Distance } \\
\text { Between } \\
\text { Strands }(\mu \mathrm{m})\end{array}$} & \multirow{2}{*}{$\begin{array}{c}\begin{array}{c}\text { Numbei } \\
\text { of 3D- } \\
\text { Plotted } \\
\text { Layers }\end{array} \\
\quad N\end{array}$} \\
\hline & & & & & $\underset{\text { (top) }}{D}$ & $\begin{array}{c}D \\
\text { (side) }\end{array}$ & $\begin{array}{c}\text { Target } \\
h\end{array}$ & $\begin{array}{c}\text { Actual } \\
h\end{array}$ & $L$ & $L+D$ & \\
\hline 300 & 1.7 & 2.5 & 115 & 300 & $\begin{array}{l}264 \\
\pm 10\end{array}$ & $315 \pm 4$ & 240 & $263 \pm 4$ & 1,000 & 1,300 & 15 \\
\hline 400 & 2.1 & 1.5 & 115 & 380 & $\begin{array}{l}377 \\
\pm 10\end{array}$ & $400 \pm 8$ & 304 & $318 \pm 16$ & 1,000 & 1,380 & 14 \\
\hline 400 & 1.7 & 1.5 & 115 & 460 & $\begin{array}{l}474 \\
\pm 34\end{array}$ & $440 \pm 7$ & 368 & $341 \pm 7$ & 1,000 & 1,460 & 12 \\
\hline
\end{tabular}

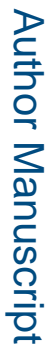

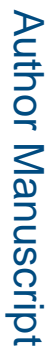

ACS Appl Bio Mater. Author manuscript; available in PMC 2020 January 15. 
Table 4.

The levels of the experimental factors and the measured responses for the I-optimal design.

\begin{tabular}{ccccccccc}
\hline Run & $\boldsymbol{X}_{\mathbf{1}}(\boldsymbol{\mu m})$ & $\boldsymbol{X}_{\mathbf{2}}(\boldsymbol{\%} \mathbf{W} / \mathbf{V})$ & $\boldsymbol{X}_{\mathbf{3}}(\boldsymbol{\%} \mathbf{W} / \mathbf{W})$ & $\boldsymbol{X}_{\mathbf{4}}\left({ }^{\circ} \mathbf{C}\right)$ & Thickness $(\mathbf{m m})$ & Density $\left(\mathbf{g} / \mathbf{c m}^{\mathbf{3}}\right)$ & Porosity $(\boldsymbol{\%})$ & Modulus $(\mathbf{M P a})$ \\
\hline 1 & 460 & 8 & 20 & 0 & 4.18 & 0.121 & 92.6 & 0.53 \\
2 & 380 & 12 & 10 & 0 & 3.98 & 0.157 & 89.3 & 3.10 \\
3 & 300 & 10 & 10 & -10 & 3.77 & 0.153 & 89.6 & 4.27 \\
4 & 460 & 12 & 20 & -20 & 4.06 & 0.138 & 91.6 & 1.16 \\
5 & 300 & 8 & 10 & 0 & 3.79 & 0.132 & 91.0 & 0.65 \\
6 & 300 & 12 & 10 & -20 & 4.01 & 0.135 & 90.8 & 1.08 \\
7 & 300 & 12 & 20 & 0 & 4.09 & 0.190 & 88.4 & 3.87 \\
8 & 300 & 12 & 0 & 0 & 3.87 & 0.163 & 87.4 & 0.65 \\
9 & 380 & 8 & 0 & -10 & 3.76 & 0.109 & 91.6 & 2.97 \\
10 & 460 & 12 & 0 & -20 & 3.86 & 0.161 & 87.6 & 2.73 \\
11 & 380 & 10 & 20 & -10 & 3.65 & 0.166 & 89.8 & 5.16 \\
12 & 380 & 10 & 10 & -20 & 3.70 & 0.126 & 91.4 & 0.06 \\
13 & 380 & 10 & 10 & -10 & 3.54 & 0.160 & 89.1 & 5.08 \\
14 & 460 & 12 & 10 & -10 & 3.95 & 0.158 & 89.3 & 2.95 \\
15 & 300 & 8 & 0 & -20 & 4.05 & 0.093 & 92.8 & 0.64 \\
16 & 300 & 8 & 20 & -20 & 3.87 & 0.116 & 92.9 & 0.55 \\
17 & 460 & 8 & 10 & -20 & 4.33 & 0.125 & 91.5 & 0.37 \\
18 & 460 & 10 & 0 & 0 & 3.93 & 0.145 & 88.8 & 2.20 \\
\hline
\end{tabular}


Table 5.

Fitted regression models of the response-factor plots (coefficient of 0 indicates a removed term). ${ }^{*}$

\begin{tabular}{|c|c|c|c|c|c|c|c|c|c|c|c|c|c|c|c|c|}
\hline Response & $R^{2}$ & $\beta_{0}$ & $\beta_{1}$ & $\beta_{2}$ & $\beta_{3}$ & $\beta_{4}$ & $\beta_{11}$ & $\beta_{22}$ & $\beta_{33}$ & $\beta_{44}$ & $\beta_{12}$ & $\beta_{13}$ & $\beta_{14}$ & $\beta_{23}$ & $\beta_{24}$ & $\beta_{34}$ \\
\hline Thickness & 0.79 & 3.647 & 0.0764 & -0.0256 & 0.0257 & -0.0241 & 0.182 & 0.197 & 0 & 0 & -0.101 & 0 & 0 & 0 & 0 & 0 \\
\hline Porosity & 0.91 & 0.897 & 0.00004 & -0.0116 & 0.0070 & -0.0066 & 0 & 0.0089 & 0 & 0 & 0 & 0.0058 & 0.0061 & 0 & 0 & 0 \\
\hline Modulus & 0.80 & 4.085 & -0.0465 & 0.571 & 0.209 & 0.395 & 0 & 0 & 0 & -2.749 & 0 & -0.725 & 0 & 0 & 0 & 0 \\
\hline
\end{tabular}

See Eq. $2-5$ for the relationships between $X_{1}-X_{4}$ and $X_{1}-X_{4}$, where $X_{1}$ is the Strand diameter $(\mu \mathrm{m}), X_{2}$ is the PLGA concentration $\left(\%\right.$ w/v), $X_{3}$ is the nHA content $(\% \mathrm{w} / \mathrm{w})$, and $X_{4}$ is the TIPS temperature $\left({ }^{\circ} \mathrm{C}\right)$. 